Article

\title{
Intrinsic Dynamic and Static Nature of Halogen Bonding in Neutral Polybromine Clusters, with the Structural Feature Elucidated by QTAIM Dual-Functional Analysis and MO Calculations
}

\author{
Satoko Hayashi *, Taro Nishide, Eiichiro Tanaka and Waro Nakanishi *(D)
}

Citation: Hayashi, S.; Nishide, T.; Tanaka, E.; Nakanishi, W. Intrinsic Dynamic and Static Nature of Halogen Bonding in Neutral Polybromine Clusters, with the Structural Feature Elucidated by QTAIM Dual-Functional Analysis and MO Calculations. Molecules 2021, 26, 2936. https://doi.org/10.3390/ molecules26102936

Academic Editor: M. Natália D. S. Cordeiro

Received: 28 April 2021

Accepted: 9 May 2021

Published: 14 May 2021

Publisher's Note: MDPI stays neutral with regard to jurisdictional claims in published maps and institutional affiliations.

Copyright: (c) 2021 by the authors. Licensee MDPI, Basel, Switzerland. This article is an open access article distributed under the terms and conditions of the Creative Commons Attribution (CC BY) license (https:// creativecommons.org/licenses/by/ $4.0 /)$.
Faculty of Systems Engineering, Wakayama University, 930 Sakaedani, Wakayama 640-8510, Japan; s209004@wakayama-u.ac.jp (T.N.); s216156@wakayama-u.ac.jp (E.T.)

* Correspondence: hayashi3@sys.wakayama-u.ac.jp (S.H.); nakanisi@sys.wakayama-u.ac.jp (W.N.); Tel.: +81-73-457-8252 (S.H. \& W.N.)

Abstract: The intrinsic dynamic and static nature of noncovalent $\mathrm{Br}-*-\mathrm{Br}$ interactions in neutral polybromine clusters is elucidated for $\mathrm{Br}_{4}-\mathrm{Br}_{12}$, applying QTAIM dual-functional analysis (QTAIMDFA). The asterisk $(*)$ emphasizes the existence of the bond critical point (BCP) on the interaction in question. Data from the fully optimized structures correspond to the static nature of the interactions. The intrinsic dynamic nature originates from those of the perturbed structures generated using the coordinates derived from the compliance constants for the interactions and the fully optimized structures. The noncovalent $\mathrm{Br}-*-\mathrm{Br}$ interactions in the L-shaped clusters of the $C_{\mathrm{s}}$ symmetry are predicted to have the typical hydrogen bond nature without covalency, although the first ones in the sequences have the vdW nature. The L-shaped clusters are stabilized by the $n(\mathrm{Br}) \rightarrow \sigma^{*}(\mathrm{Br}-\mathrm{Br})$ interactions. The compliance constants for the corresponding noncovalent interactions are strongly correlated to the $E(2)$ values based on NBO. Indeed, the MO energies seem not to contribute to stabilizing $\mathrm{Br}_{4}\left(C_{2 \mathrm{~h}}\right)$ and $\mathrm{Br}_{4}\left(D_{2 \mathrm{~d}}\right)$, but the core potentials stabilize them, relative to the case of $2 \mathrm{Br}_{2}$; this is possibly due to the reduced nuclear-electron distances, on average, for the dimers.

Keywords: ab initio calculations; quantum theory of atoms-in-molecules (QTAIM); bromide; structures

\section{Introduction}

Halogen bonding is of current and continuous interest [1,2]. A lot of information relevant to halogen bonding has been accumulated so far [3]. Halogen bonding has been discussed on the basis of the shorter distances between halogen and other atoms in crystals [4-6]. The short halogen contacts are found in two types: symmetric (type I) and bent (type II) geometries. The bonding has also been investigated in the liquid $[7,8]$ and gas [9] phases. The nature of halogen bonding has been discussed based on the theoretical background on the molecular orbital description for the bonding and the $\sigma$-hole developed on the halogen atoms, together with the stability of the structural aspects [10]. We also reported the dynamic and static nature of $\mathrm{Y}-\mathrm{X}-\pi\left(\mathrm{C}_{6} \mathrm{H}_{6}\right)$ interactions recently [11]. Halogen bonding is applied to a wide variety of fields in chemical and biological sciences, such as crystal engineering, supramolecular soft matters, and nanoparticles. Efforts have been made to unify and categorize the accumulated results and establish the concept of halogen bonding [3,12-15].

Structures of halogen molecules $\left(\mathrm{X}_{2}\right)$ have been reported, as determined by $\mathrm{X}$-ray crystallographic analysis for $\mathrm{X}=\mathrm{Cl}, \mathrm{Br}$, and I [16-18]. The behavior of bromine-bromine interactions has been reported for the optimized structures of $\mathrm{Br}_{2}-\mathrm{Br}_{5}$ in the neutral and/or charged forms, together with $\mathrm{Br}_{1}$, so far $[19,20]$. Figure 1 draws the observed structure of $\mathrm{Br}_{2}$, for example. The bromine molecules seem to exist as a zig-zag structure in the infinite chains in crystals. One would find the linear alignment of three $\mathrm{Br}$ atoms in an 
L-shaped dimer $\left(\left(\mathrm{Br}_{2}\right)_{2} ; \mathrm{Br}_{4}\right)$ and the linear alignment of four $\mathrm{Br}$ atoms in a double L-shaped trimer $\left(\left(\mathrm{Br}_{2}\right)_{3} ; \mathrm{Br}_{6}\right)$ in a planar $\mathrm{Br}_{2}$ layer in addition to $\mathrm{Br}_{2}$ itself. The linear four $\mathrm{Br}$ atoms are located in the two L-shaped dimers of $\mathrm{Br}_{6}$, overlapped at the central $\mathrm{Br}_{2}$. While the L-shaped dimers seem to construct the zig-zag type infinite chains, the linear four $\mathrm{Br}$ atoms construct linear infinite chains. The attractive $\mathrm{n}_{\mathrm{p}}(\mathrm{Br}) \rightarrow \sigma^{*}(\mathrm{Br}-\mathrm{Br}) \sigma(3 \mathrm{c}-4 \mathrm{e})$ (three centerfour electron interaction of the $\sigma$-type) and $n_{p}(B r) \rightarrow \sigma^{*}(B r-B r) \leftarrow n_{p}(B r) \sigma(4 c-6 e)$ must play a very important role to stabilize $\mathrm{Br}_{4}$ and $\mathrm{Br}_{6}$, respectively, where $n_{p}(B r)$ stands for the p-type nonbonding orbital of $\mathrm{Br}$ in the plane, perpendicular to the molecular $\mathrm{Br}_{2}$ axis, and $\sigma^{*}(\mathrm{Br}-\mathrm{Br})$ is the $\sigma^{*}$-orbital of $\mathrm{Br}_{2}$. The crystal structures of $\mathrm{Cl}_{2}$ and $\mathrm{I}_{2}$ are very similar to that of $\mathrm{Br}_{2}$.

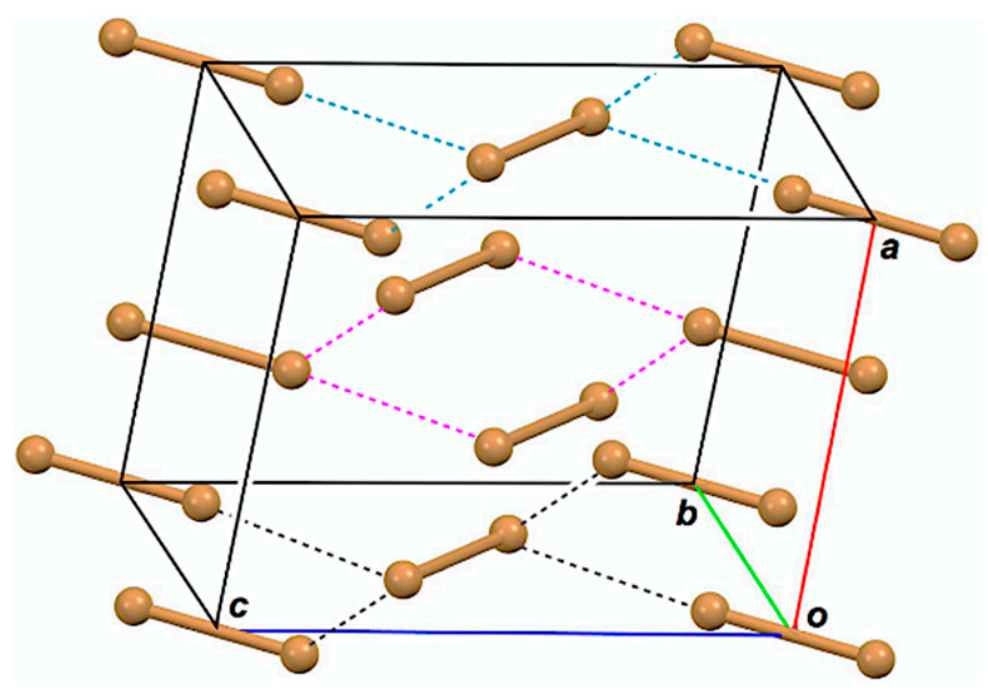

Figure 1. Structure of $\mathrm{Br}_{2}$, determined by X-ray crystallographic analysis [17].

We have been very interested in the behavior of halogen bonding in polyhalogen clusters, together with the structures. How can the interactions in the polyhalogen clusters be clarified? We propose QTAIM dual-functional analysis (QTAIM-DFA) [21-25] based on the quantum theory of atoms in molecules (QTAIM) approach introduced by Bader [26,27] to classify and characterize the various interactions effectively [28]. In QTAIM-DFA, $H_{\mathrm{b}}\left(r_{\mathrm{c}}\right)$ are plotted versus $H_{\mathrm{b}}\left(r_{\mathrm{c}}\right)-V_{\mathrm{b}}\left(r_{\mathrm{c}}\right) / 2\left(=\left(\hbar^{2} / 8 m\right) \nabla^{2} \rho_{\mathrm{b}}\left(r_{\mathrm{c}}\right)\right.$ (see Equation (SA2) in the supplementary materials), where $\rho_{\mathrm{b}}\left(r_{\mathrm{c}}\right), H_{\mathrm{b}}\left(r_{\mathrm{c}}\right)$, and $V_{\mathrm{b}}\left(r_{\mathrm{c}}\right)$ stand for the charge densities, total electron energy densities, and potential energy densities, respectively, at bond critical points (BCPs, $*$ ) on the bond paths (BPs) in this paper [26]. The kinetic energy densities at BCPs will be similarly denoted by $G_{b}\left(r_{\mathrm{c}}\right)$ [26]. A chemical bond or an interaction between $\mathrm{Br}$ and $\mathrm{Br}$ is denoted by $\mathrm{Br}-*-\mathrm{Br}$ in this work, where the asterisk emphasizes the existence of a $\mathrm{BCP}$ on a $\mathrm{BP}$ for $\mathrm{Br}-\mathrm{Br}[26,27]$. In our treatment, data from the fully optimized structures are plotted together with those from the perturbed structures around the fully optimized ones. The static nature of the interactions corresponds to the data from the fully optimized structures, which are analyzed using polar coordinate $(R, \theta)$ representation [21-25]. On the other hand, the dynamic nature originates based on the data from both the perturbed and fully optimized structures [21-25]. The plot is expressed by $\left(\theta_{p}, \kappa_{p}\right)$, where $\theta_{p}$ corresponds to the tangent line and $\kappa_{\mathrm{p}}$ is the curvature of the plot. $\theta$ and $\theta_{\mathrm{p}}$ are measured from the $y$-axis and the $y$-direction, respectively. We call $(R, \theta)$ and $\left(\theta_{\mathrm{p}}, \kappa_{\mathrm{p}}\right)$ the QTAIM-DFA parameters [29].

Interactions are classified by the signs of $\nabla^{2} \rho_{\mathrm{b}}\left(r_{\mathrm{c}}\right)$ and $H_{\mathrm{b}}\left(r_{\mathrm{c}}\right)$, based on the QTAIM approach. The interactions are called shard shell (SS) interactions when $\nabla^{2} \rho_{\mathrm{b}}\left(r_{\mathrm{c}}\right)<0$ and closed-shell (CS) interactions when $\nabla^{2} \rho_{\mathrm{b}}\left(r_{\mathrm{c}}\right)>0$ [26]. In particular, CS interactions are called pure CS ( $p$-CS) interactions when $H_{\mathrm{b}}\left(r_{\mathrm{c}}\right)>0$ and $\nabla^{2} \rho_{\mathrm{b}}\left(r_{\mathrm{c}}\right)>0$. We call interactions where $H_{\mathrm{b}}\left(r_{\mathrm{c}}\right)<0$ and $\nabla^{2} \rho_{\mathrm{b}}\left(r_{\mathrm{c}}\right)>0$ regular CS $(r$-CS $)$ interactions, which clearly distinguishes 
these interactions from the $p$-CS interactions. The signs of $\nabla^{2} \rho_{\mathrm{b}}\left(r_{\mathrm{c}}\right)$ can be replaced by those of $H_{\mathrm{b}}\left(r_{\mathrm{c}}\right)-V_{\mathrm{b}}\left(r_{\mathrm{c}}\right) / 2$ because $\left(\hbar^{2} / 8 m\right) \nabla^{2} \rho_{\mathrm{b}}\left(r_{\mathrm{c}}\right)=H_{\mathrm{b}}\left(r_{\mathrm{c}}\right)-V_{\mathrm{b}}\left(r_{\mathrm{c}}\right) / 2$ (see Equation (SA2) in the supporting information). Indeed, $H_{\mathrm{b}}\left(r_{\mathrm{c}}\right)-V_{\mathrm{b}}\left(r_{\mathrm{c}}\right) / 2=0$ corresponds to the borderline between the classic covalent bonds of SS and the noncovalent interactions of CS, but $H_{\mathrm{b}}\left(r_{\mathrm{c}}\right)$ $=0$ appears to be buried in the noncovalent interactions of CS. As a result, it is difficult to characterize the various CS interactions based on the signs of $H_{\mathrm{b}}\left(r_{\mathrm{c}}\right)-V_{\mathrm{b}}\left(r_{\mathrm{c}}\right) / 2$ and /or $H_{\mathrm{b}}\left(r_{\mathrm{c}}\right)$. In QTAIM-DFA, the signs of the first derivatives of $H_{\mathrm{b}}\left(r_{\mathrm{c}}\right)-V_{\mathrm{b}}\left(r_{\mathrm{c}}\right) / 2$ and $H_{\mathrm{b}}\left(r_{\mathrm{c}}\right)$ $\left(\mathrm{d}\left(H_{\mathrm{b}}\left(r_{\mathrm{c}}\right)-V_{\mathrm{b}}\left(r_{\mathrm{c}}\right) / 2\right) / \mathrm{d} r\right.$ and $\mathrm{d} H_{\mathrm{b}}\left(r_{\mathrm{c}}\right) / \mathrm{d} r$, respectively, where $r$ is the interaction distance) are used to characterize CS interactions, in addition to those of $H_{\mathrm{b}}\left(r_{\mathrm{c}}\right)-V_{\mathrm{b}}\left(r_{\mathrm{c}}\right) / 2$ and $H_{\mathrm{b}}\left(r_{\mathrm{c}}\right)$, after analysis of the plot. While the former corresponds to $\left(\theta_{\mathrm{p}}, \kappa_{\mathrm{p}}\right)$, the latter does to $(R, \theta)$. The analysis of the plots enables us to characterize the various CS interactions more effectively. Again, the details are explained later.

The perturbed structures necessary for QTAIM-DFA can be generated. Among them, a method employing the coordinates corresponding to the compliance constants $C_{i i}$ for internal vibrations is shown to be highly reliable to generate the perturbed structures [30-39]. The method, which we proposed recently, is called CIV. The dynamic nature of interactions based on the perturbed structures with CIV is described as the "intrinsic dynamic nature of interactions" since the coordinates are invariant to the choice of coordinate system. Rough criteria that distinguish the interaction in question from others are obtained by applying QTAIM-DFA with CIV to standard interactions. QTAIM-DFA and the criteria are explained in the appendix of the supplementary materials using Schemes SA1-SA3, Figures SA1 and SA2, Table SA1, and Equations (SA1)-(SA7). The basic concept of the QTAIM approach is also explained.

QTAIM-DFA, using the perturbed structures generated with CIV, is well-suited to elucidate the intrinsic dynamic and static nature of halogen-halogen interactions in the polyhalogen clusters. As the first step to clarify the nature of various types of halogenhalogen interactions in the polyhalogen clusters, the nature of each bromine-bromine interaction in the neutral polybromine clusters is elucidated by applying QTAIM-DFA. Various types of structures and interactions are found in the optimized structures of polybromine clusters, other than those observed in the crystals. Here, we present the results of investigations on the polybromine clusters, together with the structural feature, elucidated with QTAIM-DFA and QC calculations.

\section{Methodological Details in Calculations}

The structures were optimized by employing Gaussian 09 programs [40]. The 6-311+G(3df) basis [41-44] set was applied to optimize the structures of neutral polybromine clusters, $\mathrm{Br}_{2}-$ $\mathrm{Br}_{12}$. The Møller-Plesset second-order energy correlation (MP2) level [45-47] was applied for the optimizations. Optimized structures were confirmed by frequency analysis. The results of the frequency analyses were employed to calculate the $C_{i j}$ values and coordinates corresponding to $C_{i i}[30,34-36]$. The $\rho_{\mathrm{b}}\left(r_{\mathrm{c}}\right), H_{\mathrm{b}}\left(r_{\mathrm{c}}\right)-V_{\mathrm{b}}\left(r_{\mathrm{c}}\right) / 2\left(=\left(\hbar^{2} / 8 m\right) \nabla^{2} \rho_{\mathrm{b}}\left(r_{\mathrm{c}}\right)\right)$, and $H_{\mathrm{b}}\left(r_{\mathrm{c}}\right)$ values were calculated using the Gaussian 09 program package [40], with the same method applied to the optimizations. Data were analyzed with the AIM2000 [48,49] and AIMAll [50] programs.

Coordinates corresponding to the compliance constants for an internal coordinate $i$ of the internal vibrations $\left(\mathbf{C}_{i}\right)$ were employed to generate the perturbed structures necessary in QTAIM-DFA [21-25]. Equation (1) explains the method to generate the perturbed structures with CIV. An $i$-th perturbed structure in question $\left(\mathbf{S}_{i w}\right)$ was generated by the addition of the coordinates $\left(\mathbf{C}_{i}\right)$ corresponding to $C_{i i}$ to the standard orientation of a fully optimized structure $\left(\mathbf{S}_{\mathrm{o}}\right)$ in the matrix representation. The coefficient $g_{i w}$ in Equation (1) controls the difference in structures between $\mathbf{S}_{i w}$ and $\mathbf{S}_{\mathrm{o}}$ : $g_{i w}$ are determined to satisfy Equation (2) for the interaction in question, where $r$ and $r_{\mathrm{o}}$ show the distances in question in the perturbed and fully optimized structures, respectively, with $a_{\mathrm{o}}$ of Bohr radius (0.52918 $\AA$ ) [21-25,30].

$$
\mathbf{S}_{i w}=\mathbf{S}_{\mathrm{o}}+g_{i w} \times \mathbf{C}_{i}
$$




$$
\begin{gathered}
r=r_{\mathrm{O}}+w a_{\mathrm{O}}\left(w=(0), \pm 0.05 \text { and } \pm 0.1 ; a_{\mathrm{o}}=0.52918 \AA\right) \\
y=c_{\mathrm{O}}+c_{1} x+c_{2} x^{2}+c_{3} x^{3} \quad\left(R_{\mathrm{c}}{ }^{2}: \text { square of correlation coefficient }\right)
\end{gathered}
$$

In the QTAIM-DFA treatment, $H_{\mathrm{b}}\left(\boldsymbol{r}_{\mathrm{c}}\right)$ are plotted versus $H_{\mathrm{b}}\left(\boldsymbol{r}_{\mathrm{c}}\right)-V_{\mathrm{b}}\left(\boldsymbol{r}_{\mathrm{c}}\right) / 2$ for the data of five points of $w=0, \pm 0.05$, and \pm 0.1 in Equation (2). Each plot is analyzed using a regression curve of the cubic function, as shown in Equation (3), where $(x, y)=\left(H_{\mathrm{b}}\left(\boldsymbol{r}_{\mathrm{c}}\right)-\right.$ $\left.V_{\mathrm{b}}\left(r_{\mathrm{c}}\right) / 2, H_{\mathrm{b}}\left(r_{\mathrm{c}}\right)\right)\left(R_{\mathrm{c}}^{2}\right.$ (square of correlation coefficient) $>0.99999$ in the norm) [25].

\section{Results and Discussion}

\subsection{Structural Optimizations of Polybromine Clusters, $\mathrm{Br}_{6}-\mathrm{Br}_{12}$}

Structures of the neutral $\mathrm{Br}_{2}-\mathrm{Br}_{12}$ clusters were optimized with $\mathrm{MP} 2 / 6-311+\mathrm{G}(3 \mathrm{df})$. The structural parameters for the optimized structures of minima for $\mathrm{Br}_{2}-\mathrm{Br}_{6}$ and $\mathrm{Br}_{8}-\mathrm{Br}_{12}$ are collected in Tables S1 and S2, respectively. Some transition states (TSs) for $\mathrm{Br}_{4}$ and $\mathrm{Br}_{6}$ were also calclaterd. The notation of $C_{\mathrm{s}}-\mathrm{L}_{m}(m=1-5)$ is used for the linear L-shaped clusters of the $C_{\mathrm{s}}$ symmetry, where $m$ stands for the number of noncovalent interactions in $\mathrm{Br}_{2 m+2}(m=1-5)$. Cyclic structures are also optimized, retaining the higher symmetries. The optimized structures are not shown in figures, but they can be found in the molecular graphs with the contour maps of $\rho(r)$ for the linear-type bromine clusters $\mathrm{Br}_{4}-\mathrm{Br}_{12}\left(C_{\mathrm{s}}-\mathrm{L}_{m}\right.$ $(m=1-5))$ and for the cyclic bromine clusters $\mathrm{Br}_{4}-\mathrm{Br}_{12}$, drawn on the optimized structures with MP2/6-311+G(3df) [51]. The energies for the formation of $\mathrm{Br}_{4}-\mathrm{Br}_{6}$ and $\mathrm{Br}_{8}-\mathrm{Br}_{12}$ are given in Tables S1 and S2, respectively, from the components $\left(\Delta E=E\left(\mathrm{Br}_{2 k}\right)-k E\left(\mathrm{Br}_{2}\right)\right)$ on the energy surfaces $\left(\Delta E_{\mathrm{ES}}\right)$ and those with the collections of zero-point energies $\left(\Delta E_{\mathrm{ZP}}\right)$. The $\Delta E_{\mathrm{ZP}}$ values were plotted versus $\Delta E_{\mathrm{ES}}$. The plot is shown in Figure S1, which gives an excellent correlation $\left(y=0.940 x+0.129 ; R_{\mathrm{C}}{ }^{2}\right.$ (square of correlation coefficient) $\left.=0.9999\right)$ [52] Therefore, the $\Delta E_{\mathrm{ES}}$ values are employed for the discussion.

The behavior of the neutral dibromine clusters $\left(\mathrm{Br}_{4}\right)$ is discussed first. Three structures were optimized for $\mathrm{Br}_{4}$ as minima with some TSs. The minima are the L-shaped structure of $C_{\mathrm{s}}$ symmetry $\left(\mathrm{Br}_{4}\left(C_{\mathrm{s}}-\mathrm{L}_{1}\right)\right)$ [19], the cyclic structure of $C_{2 \mathrm{~h}}$ symmetry $\left(\mathrm{Br}_{4}\left(C_{2 \mathrm{~h}}\right)\right)$, and the tetrahedral type of $D_{2 \mathrm{~d}}$ symmetry $\left(\mathrm{Br}_{4}\left(D_{2 \mathrm{~d}}\right)\right)$. A TS of the $C_{\mathrm{s}}$ symmetry was detected between $\mathrm{Br}_{4}\left(C_{\mathrm{s}}-\mathrm{L}_{1}\right)$ and $\mathrm{Br}_{4}\left(C_{2 \mathrm{~h}}\right)$, and two TSs of the $C_{1}$ symmetry were between $\mathrm{Br}_{4}\left(C_{2 \mathrm{~h}}\right)$ and $\mathrm{Br}_{4}\left(D_{2 \mathrm{~d}}\right)$ and between $\mathrm{Br}_{4}\left(D_{2 \mathrm{~d}}\right)$ and $\mathrm{Br}_{4}\left(C_{\mathrm{s}}-\mathrm{L}_{1}\right)$. They are called TS $\left(C_{\mathrm{s}}: C_{\mathrm{s}}, C_{2 \mathrm{~h}}\right)$, TS $\left(C_{1}: C_{2 h}, D_{2 d}\right)$, and TS $\left(C_{1}: D_{2 d}, C_{s}\right)$, respectively. The three minima will be converted to each other through the three TSs. A TS between $\mathrm{Br}_{4}\left(C_{\mathrm{s}}-\mathrm{L}_{1}\right)$ and its topological isomer was also detected, which is called TS $\left(C_{2 \mathrm{v}}: C_{\mathrm{s}}, C_{\mathrm{s}}\right)$; however, further effort was not made to search for similar TSs between $\mathrm{Br}_{4}\left(C_{2 \mathrm{~h}}\right)$ and its topological isomer and between $\mathrm{Br}_{4}\left(C_{2 \mathrm{~d}}\right)$ and its topological isomer.

Figure 2 draws the energy profiles for the optimized structures of minima, $\mathrm{Br}_{4}\left(\mathrm{C}_{\mathrm{s}}-\mathrm{L}_{1}\right)$, $\mathrm{Br}_{4}\left(C_{2 \mathrm{~h}}\right)$, and $\mathrm{Br}_{4}\left(D_{2 \mathrm{~d}}\right)$, together with the TSs TS $\left(C_{\mathrm{s}}: C_{\mathrm{s}}, C_{2 \mathrm{~h}}\right), \mathrm{TS}\left(C_{\mathrm{s}}: C_{2 \mathrm{~h}}, D_{2 \mathrm{~d}}\right)$, TS $\left(C_{1}\right.$ : $\left.C_{2 \mathrm{~d}}, C_{\mathrm{s}}\right)$, and TS $\left(C_{2 \mathrm{v}}: C_{\mathrm{s}}, C_{\mathrm{s}}\right)$. The optimized structures are not shown in the figures, but they can be found in the molecular graphs shown in Figure 2, illustrated on the optimized structures. All BCPs expected are detected clearly, together with RCPs and a CCP [26]. The $\Delta E_{\mathrm{ES}}$ value of $-10.7 \mathrm{~kJ} \mathrm{~mol}{ }^{-1}$ for the formation of $\mathrm{Br}_{4}\left(C_{\mathrm{s}}-\mathrm{L}_{1}\right)$ seems very close to the border area between the vdW and typical hydrogen bond $(t-\mathrm{HB})$ adducts. The driving force for the formation of $\mathrm{Br}_{4}\left(C_{\mathrm{s}}-\mathrm{L}_{1}\right)$ must be $\mathrm{Br}_{3} \sigma(3 \mathrm{c}-4 \mathrm{e})$ of the $n_{\mathrm{p}}(\mathrm{Br}) \rightarrow \sigma^{*}(\mathrm{Br}-\mathrm{Br})$ type. The interactions in $\mathrm{Br}_{4}\left(C_{2 \mathrm{~h}}\right)$ and $\mathrm{Br}_{4}\left(D_{2 \mathrm{~d}}\right)$ seem very different from those in $\mathrm{Br}_{4}\left(C_{\mathrm{s}}-\mathrm{L}_{1}\right)$. The $\Delta E_{\mathrm{ES}}$ values of $\mathrm{Br}_{4}\left(C_{2 \mathrm{~h}}\right)\left(-8.0 \mathrm{~kJ} \mathrm{~mol}^{-1}\right)$ and $\mathrm{Br}_{4}\left(D_{2 \mathrm{~d}}\right)\left(-9.1 \mathrm{~kJ} \mathrm{~mol}^{-1}\right)$ are close to that for $\mathrm{Br}_{4}\left(C_{\mathrm{s}}-\mathrm{L}_{1}\right)\left(-10.7 \mathrm{~kJ} \mathrm{~mol}^{-1}\right)$. Moreover, the values for TS $\left(C_{\mathrm{s}}: C_{\mathrm{s}}, C_{2 \mathrm{~h}}\right)(-7.4 \mathrm{~kJ}$ $\left.\mathrm{mol}^{-1}\right)$, TS $\left(C_{1}: C_{2 \mathrm{~h}}, D_{2 \mathrm{~d}}\right)\left(-7.6 \mathrm{~kJ} \mathrm{~mol}^{-1}\right)$, TS $\left(C_{1}: D_{2 \mathrm{~d}}, C_{\mathrm{s}}\right)\left(-7.0 \mathrm{~kJ} \mathrm{~mol}^{-1}\right)$, and TS $\left(C_{2 \mathrm{v}}\right.$ : $\left.C_{\mathrm{s}}, C_{\mathrm{s}}\right)\left(-8.7 \mathrm{~kJ} \mathrm{~mol}^{-1}\right)$ are not so different from those for the minima. 


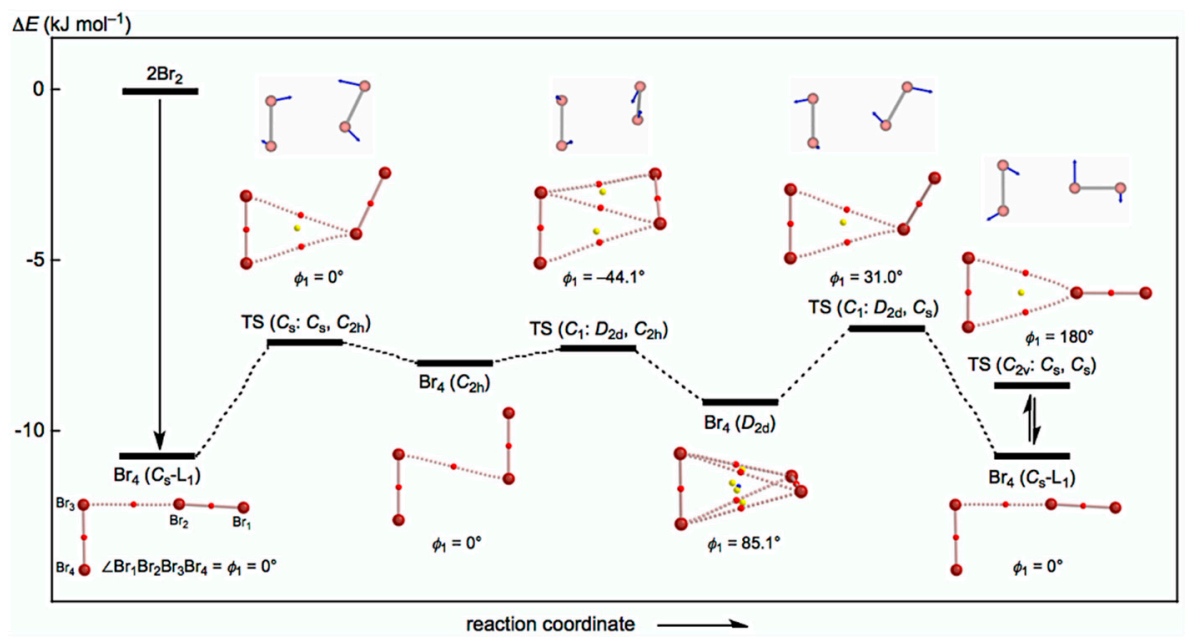

Figure 2. Energy profile with molecular graphs for the structures of $\mathrm{Br}_{4}$ clusters, optimized with $\mathrm{MP} 2 / 6-311+\mathrm{G}(3 \mathrm{df})$.

In the case of $\mathrm{Br}_{6}$, three structures of the linear $C_{\mathrm{s}}$ symmetry $\left(\mathrm{Br}_{6}\left(C_{\mathrm{s}}-\mathrm{L}_{2}\right)\right)$, the linear $C_{2}$ symmetry $\left(\operatorname{Br}_{6}\left(C_{2}\right)\right)$, and the cyclic $C_{3 \mathrm{~h}}$ symmetry $\left(\operatorname{Br}_{6}\left(C_{3 \mathrm{~h}}-c\right)\right)$ were optimized typically as minima. The linear $\mathrm{Br}_{6}$ clusters of $C_{2 \mathrm{~h}}$ symmetry $\left(\mathrm{Br}_{6}\left(C_{2 \mathrm{~h}}\right)\right)$ and $C_{2 \mathrm{v}}$ symmetry $\left(\mathrm{Br}_{6}\left(C_{2 \mathrm{v}}\right)\right)$, similar to $\mathrm{Br}_{6}\left(C_{2}\right)$, were also optimized, of which the torsional angles, $\phi\left({ }^{1} \mathrm{Br}^{2} \mathrm{Br}^{5} \mathrm{Br}{ }^{6} \mathrm{Br}\right)$ $\left(=\phi_{3}\right)$, were $0^{\circ}$ and $180^{\circ}$, respectively. One imaginary frequency was detected for each; therefore, they are assigned to TSs between $\mathrm{Br}_{6}\left(C_{2}\right)$ and the topological isomer on the different reaction coordinates. Further effort was not made to search for TSs.

The $\Delta E_{\mathrm{ES}}$ value for $\mathrm{Br}_{6}\left(C_{\mathrm{s}}-\mathrm{L}_{2}\right)$ was predicted to be $-22.6 \mathrm{~kJ} \mathrm{~mol}^{-1}$. The magnitude is slightly larger than the double value for $\mathrm{Br}_{4}\left(C_{\mathrm{s}}-\mathrm{L}_{1}\right)\left(\Delta E_{\mathrm{ES}}=-10.7 \mathrm{~kJ} \mathrm{~mol}^{-1}\right)$. Two types of $\sigma(3 c-4 e)$ operate to stabilize $\mathrm{Br}_{6}\left(C_{\mathrm{s}}-\mathrm{L}_{2}\right)$. One, $\sigma(3 \mathrm{c}-4 \mathrm{e})$, seems similar to that in $\mathrm{Br}_{4}\left(C_{\mathrm{s}}-\mathrm{L}_{1}\right)$, but the other would be somewhat different. Namely, the second interaction would contribute to $\Delta E_{\mathrm{ES}}$ somewhat more than that of the first one in the formation of $\mathrm{Br}_{6}$ $\left(C_{\mathrm{s}}-\mathrm{L}_{2}\right)$. On the other hand, the linear interaction in $\mathrm{Br}_{6}\left(C_{2}\right)$ can be explained by $\sigma(4 \mathrm{c}-6 \mathrm{e})$ of the $n_{\mathrm{p}}(\mathrm{Br}) \rightarrow \sigma^{*}(\mathrm{Br}-\mathrm{Br}) \leftarrow n_{\mathrm{p}}(\mathrm{Br})$ type. The magnitude of $\Delta E_{\mathrm{ES}}$ of $\mathrm{Br}_{6}\left(C_{2}\right)$ seems slightly smaller than that of $\mathrm{Br}_{6}\left(C_{\mathrm{s}}-\mathrm{L}_{2}\right)$ but is very close to the double value for $\mathrm{Br}_{4}\left(C_{\mathrm{s}}-\mathrm{L}_{1}\right)$. The magnitude of $\Delta E_{\mathrm{ES}}$ for $\mathrm{Br}_{6}\left(C_{3 \mathrm{~h}}-\mathrm{c}\right)$ is close to the triple value of $\mathrm{Br}_{4}\left(C_{\mathrm{s}}-\mathrm{L}_{1}\right)$. One finds triply degenerated $\sigma(3 \mathrm{c}-4 \mathrm{e})$ interactions in $\mathrm{Br}_{6}\left(C_{3 \mathrm{~h}}-c\right)$. The similarity in the interactions for $\mathrm{Br}_{4}\left(C_{\mathrm{s}}-\mathrm{L}_{1}\right), \mathrm{Br}_{6}\left(C_{2}\right)$, and $\mathrm{Br}_{6}\left(C_{3 \mathrm{~h}^{-}} \mathrm{c}\right)$ will be discussed again later. The magnitudes of $\Delta E_{\mathrm{ES}}$ become proportionally larger to the size of the clusters, as shown in Figures S1 and S2. The $\Delta E_{\mathrm{ES}}$ values are plotted versus $k$ in $\mathrm{Br}_{2 k}(2 \leq k \leq 6)$ for the $C_{\mathrm{s}}-\mathrm{L}_{m}$ type. The results are shown in Figure S2. Contributions from inner $\sigma(3 \mathrm{c}-4 \mathrm{e})$ (named $r_{\text {in }}$ ) to $\Delta E_{\mathrm{ES}}$ seem slightly larger than those from $\sigma(3 \mathrm{c}-4 \mathrm{e})$ in the front end and end positions (named $r_{2}$ and $r_{\omega}$, respectively).

After examination of the optimized structures, the next extension is to clarify the nature of $\mathrm{Br}-*-\mathrm{Br}$ interactions by applying QTAIM-DFA. The contour plots are discussed next.

\subsection{Molecular Graphs with Contour Plots of Polybromine Clusters}

Figure 3 illustrates the molecular graphs with contour maps of $\rho(r)$ for the linear type of $\mathrm{Br}_{4}\left(C_{\mathrm{s}}-\mathrm{L}_{1}\right)-\mathrm{Br}_{12}\left(C_{\mathrm{s}}-\mathrm{L}_{5}\right)$, drawn on the structures optimized with MP2/6-311+G(3df). Figure 4 draws the molecular graphs with contour maps of $\rho(r)$ for $\mathrm{Br}_{4}-\mathrm{Br}_{12}$, other than those for $\mathrm{Br}_{4}\left(C_{\mathrm{s}}-\mathrm{L}_{1}\right)-\mathrm{Br}_{12}\left(C_{\mathrm{s}}-\mathrm{L}_{5}\right)$, calculated with MP2/6-311+G(3df) $[53,54]$ (see also Figure S3). All BCPs expected are detected clearly, together with RCPs and a CCP containing those for noncovalent $\mathrm{Br}-*-\mathrm{Br}$ interactions, which are located at the (three-dimensional) saddle points of $\rho(r)$. 

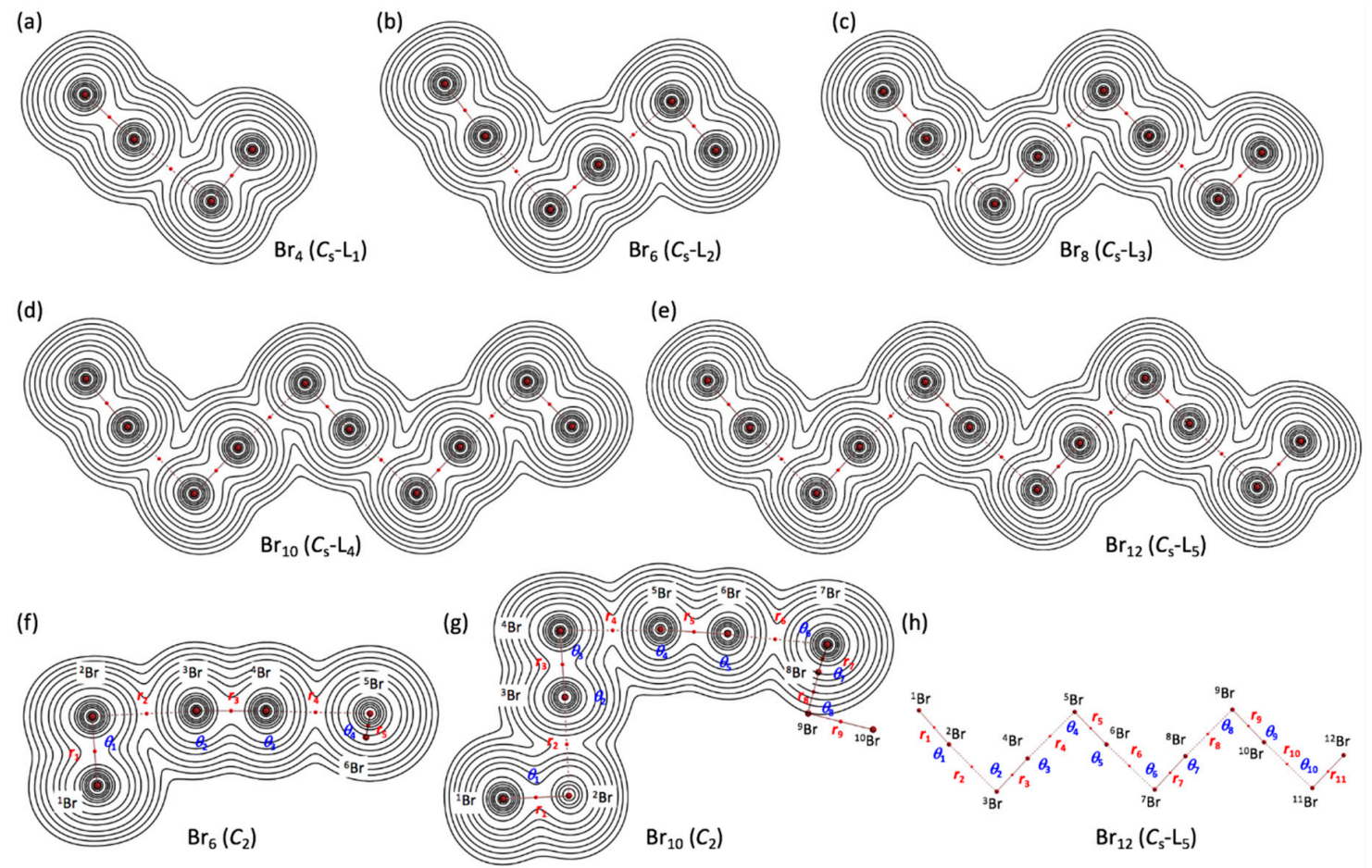

Figure 3. Molecular graphs with contour plots of $\rho(r)$ for the linear-type bromine clusters of $\mathrm{Br}_{4}-\mathrm{Br}_{12}$, calculated with MP2/6-311+G(3df). (a-e) for the linear $C_{\mathrm{s}}-\mathrm{L}_{m}$ type, (f, $\left.\mathbf{g}\right)$ for the $C_{2}$ type, and (h) for the notations of atoms, bonds, and angles, exemplified by $\mathrm{B}_{12}\left(\mathrm{C}_{\mathrm{s}}-\mathrm{L}_{5}\right)$. BCPs are denoted by red dots, and BPs (bond paths) are by pink lines. Bromine atoms are in reddish-brown.

(a)

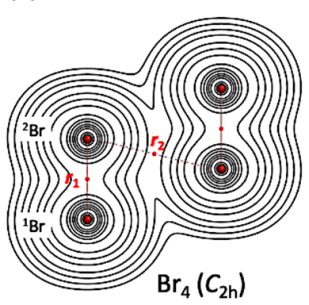

(e)

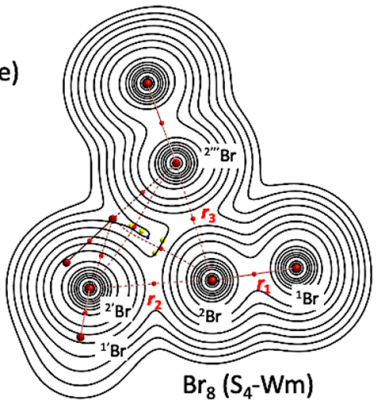

(b)

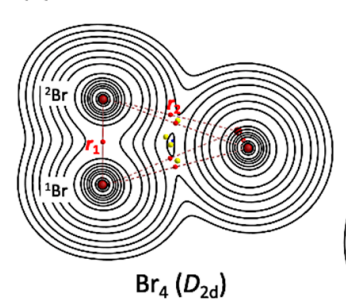

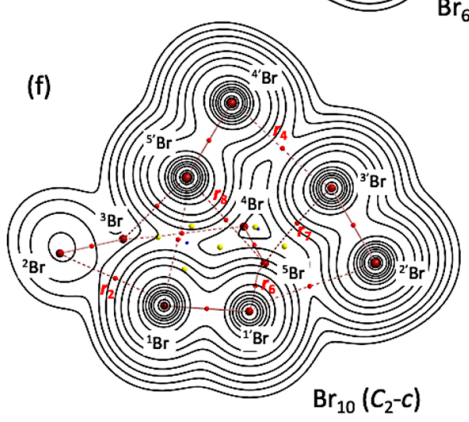

(d)
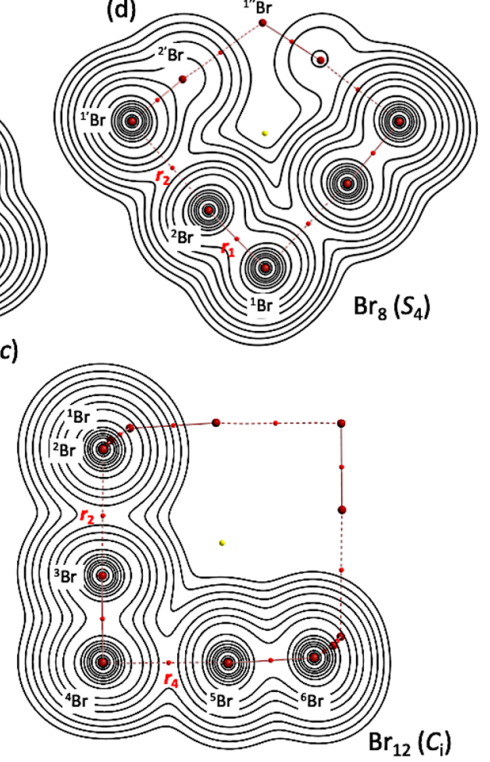

Figure 4. Molecular graphs with contour plots of $\rho(r)$ for the cyclic bromine clusters of $\mathrm{Br}_{4}-\mathrm{Br}_{12}$, (a-g), calculated with MP2/6-311+G(3df). BCPs are denoted by red dots, RCPs (ring-critical points) by yellow dots, CCPs (cage-critical points) by blue dots, and BPs (bond paths) by pink lines. See ref. [55] for (a).

\subsection{Survey of the Br-*-Br Interactions in Polybromine Clusters}

As shown in Figures 2-4, the BPs in $\mathrm{Br}_{4}-\mathrm{Br}_{12}$ seem almost straight. The linearity is confirmed by comparing the lengths of BPs $\left(r_{\mathrm{BP}}\right)$ with the corresponding straight-line distances $\left(R_{\mathrm{SL}}\right)$. The $r_{\mathrm{BP}}$ and $R_{\mathrm{SL}}$ values are collected in Table S3, together with the differences 
between them, $\Delta r_{\mathrm{BP}}\left(=r_{\mathrm{BP}}-R_{\mathrm{SL}}\right)$. The magnitudes of $\Delta r_{\mathrm{BP}}$ are less than $0.01 \AA$, except for $r_{2}$ in $\mathrm{Br}_{4}\left(C_{2 \mathrm{v}}\right)\left(\Delta r_{\mathrm{BP}}=0.014 \AA\right), r_{3}$ in $\mathrm{Br}_{8}\left(S_{4}-\mathrm{Wm}\right)(0.014 \AA)$, and $r_{2}$ in $\mathrm{Br}_{10}\left(C_{2}-c\right)(0.012 \AA)$. Consequently, all BPs in $\mathrm{Br}_{4}-\mathrm{Br}_{12}$ can be approximated as straight lines.

The $\rho_{\mathrm{b}}\left(r_{\mathrm{c}}\right), H_{\mathrm{b}}\left(r_{\mathrm{c}}\right)-V_{\mathrm{b}}\left(r_{\mathrm{c}}\right) / 2\left(=\left(\hbar^{2} / 8 m\right) \nabla^{2} \rho_{\mathrm{b}}\left(r_{\mathrm{c}}\right)\right)$, and $H_{\mathrm{b}}\left(r_{\mathrm{c}}\right)$ values are calculated for the $\mathrm{Br}-*-\mathrm{Br}$ interactions at $\mathrm{BCPs}$ in the structures of $\mathrm{Br}_{2}-\mathrm{Br}_{12}$, optimized with MP2/6$311+\mathrm{G}$ (3df) [53-55]. Table 1 collects the values for the noncovalent $\mathrm{Br}-*-\mathrm{Br}$ interactions in $\mathrm{Br}_{4}-\mathrm{Br}_{12}$ of the $C_{\mathrm{s}}-\mathrm{L}_{m}$ type. Table 2 summarizes the values for the noncovalent $\mathrm{Br}-*-\mathrm{Br}$ interactions in $\mathrm{Br}_{4}-\mathrm{Br}_{12}$, other than those of the $C_{\mathrm{s}}-\mathrm{L}_{m}$ type. $H_{\mathrm{b}}\left(r_{\mathrm{c}}\right)$ are plotted versus $H_{\mathrm{b}}\left(r_{\mathrm{c}}\right)-V_{\mathrm{b}}\left(r_{\mathrm{c}}\right) / 2$ for the data shown in Tables 1 and 2, together with those from the perturbed structures generated with CIV. Figure 5 shows the plots for the noncovalent $\mathrm{Br}-*-\mathrm{Br}$ interactions and covalent $\mathrm{Br}-*-\mathrm{Br}$ bonds, exemplified by $\mathrm{Br}_{10}\left(\mathrm{C}_{\mathrm{s}}-\mathrm{L}_{4}\right)$.

Table 1. The $\rho_{\mathrm{b}}\left(r_{\mathrm{c}}\right), H_{\mathrm{b}}\left(r_{\mathrm{c}}\right)-V_{\mathrm{b}}\left(r_{\mathrm{c}}\right) / 2\left(=\left(\hbar^{2} / 8 m\right) \nabla^{2} \rho_{\mathrm{b}}\left(r_{\mathrm{c}}\right)\right)$, and $H_{\mathrm{b}}\left(\boldsymbol{r}_{\mathrm{c}}\right)$ values and QTAIM-DFA parameters for Br- $*-\mathrm{Br}$ at BCPs in $\mathrm{Br}_{4}\left(C_{\mathrm{s}}-\mathrm{L}_{1}\right)-\mathrm{Br}_{12}\left(C_{\mathrm{s}}-\mathrm{L}_{5}\right)$, together with $\mathrm{Br}_{10}\left(C_{2}\right)$ and $\mathrm{Br}_{2}$, evaluated with $\mathrm{MP} 2 / 6-311+\mathrm{G}(3 \mathrm{df})^{1}$.

\begin{tabular}{|c|c|c|c|c|c|c|}
\hline Species & BCP on & $\rho_{\mathrm{b}}\left(r_{\mathrm{c}}\right)$ & $c \nabla^{2} \rho_{\mathrm{b}}\left(r_{\mathrm{c}}\right)^{2}$ & $H_{b}\left(r_{c}\right)$ & $R^{3}$ & $\theta^{4}$ \\
\hline (Symmetry) & & (au) & (au) & (au) & (au) & $\left({ }^{\circ}\right)$ \\
\hline $\mathrm{Br}_{4}\left(\mathrm{C}_{\mathrm{s}}-\mathrm{L}_{1}\right)$ & $r_{2}$ & 0.0109 & 0.0045 & 0.0014 & 0.0048 & 72.5 \\
\hline $\mathrm{Br}_{6}\left(\mathrm{C}_{\mathrm{s}}-\mathrm{L}_{2}\right)$ & $r_{2}$ & 0.0113 & 0.0047 & 0.0014 & 0.0049 & 73.0 \\
\hline $\mathrm{Br}_{6}\left(\mathrm{C}_{\mathrm{s}}-\mathrm{L}_{2}\right)$ & $r_{4}$ & 0.0119 & 0.0049 & 0.0014 & 0.0051 & 73.7 \\
\hline $\mathrm{Br}_{8}\left(\mathrm{C}_{\mathrm{s}}-\mathrm{L}_{3}\right)$ & $r_{2}$ & 0.0114 & 0.0047 & 0.0014 & 0.0049 & 73.2 \\
\hline $\mathrm{Br}_{8}\left(\mathrm{C}_{\mathrm{s}}-\mathrm{L}_{3}\right)$ & $r_{4}$ & 0.0124 & 0.0050 & 0.0014 & 0.0052 & 74.4 \\
\hline $\mathrm{Br}_{8}\left(\mathrm{C}_{\mathrm{s}}-\mathrm{L}_{3}\right)$ & $r_{6}$ & 0.0120 & 0.0049 & 0.0014 & 0.0051 & 73.9 \\
\hline $\mathrm{Br}_{10}\left(\mathrm{C}_{\mathrm{s}}-\mathrm{L}_{4}\right)$ & $r_{2}$ & 0.0114 & 0.0047 & 0.0014 & 0.0049 & 73.2 \\
\hline $\mathrm{Br}_{10}\left(\mathrm{C}_{\mathrm{s}}-\mathrm{L}_{4}\right)$ & $r_{4}$ & 0.0125 & 0.0051 & 0.0014 & 0.0053 & 74.6 \\
\hline $\mathrm{Br}_{10}\left(\mathrm{C}_{\mathrm{s}}-\mathrm{L}_{4}\right)$ & $r_{6}$ & 0.0125 & 0.0051 & 0.0014 & 0.0053 & 74.6 \\
\hline $\mathrm{Br}_{10}\left(\mathrm{C}_{\mathrm{s}}-\mathrm{L}_{4}\right)$ & $r_{8}$ & 0.0120 & 0.0049 & 0.0014 & 0.0051 & 73.9 \\
\hline $\mathrm{Br}_{12}\left(\mathrm{C}_{\mathrm{s}}-\mathrm{L}_{5}\right)$ & $r_{2}$ & 0.0114 & 0.0047 & 0.0014 & 0.0049 & 73.2 \\
\hline $\mathrm{Br}_{12}\left(\mathrm{C}_{\mathrm{s}}-\mathrm{L}_{5}\right)$ & $r_{4}$ & 0.0126 & 0.0051 & 0.0014 & 0.0053 & 74.7 \\
\hline $\mathrm{Br}_{12}\left(\mathrm{C}_{\mathrm{s}}-\mathrm{L}_{5}\right)$ & $r_{6}$ & 0.0127 & 0.0051 & 0.0014 & 0.0053 & 74.7 \\
\hline $\mathrm{Br}_{12}\left(\mathrm{C}_{\mathrm{s}}-\mathrm{L}_{5}\right)$ & $r_{8}$ & 0.0126 & 0.0051 & 0.0014 & 0.0053 & 74.7 \\
\hline $\mathrm{Br}_{12}\left(\mathrm{C}_{\mathrm{s}}-\mathrm{L}_{5}\right)$ & $r_{10}$ & 0.0120 & 0.0049 & 0.0014 & 0.0051 & 73.9 \\
\hline $\mathrm{Br}_{6}\left(C_{2}\right)$ & $r_{2}$ & 0.0104 & 0.0044 & 0.0014 & 0.0046 & 72.1 \\
\hline $\mathrm{Br}_{10}\left(C_{2}\right)$ & $r_{2}$ & 0.0118 & 0.0048 & 0.0014 & 0.0050 & 73.6 \\
\hline $\mathrm{Br}_{10}\left(C_{2}\right)$ & $r_{4}$ & 0.0106 & 0.0044 & 0.0014 & 0.0046 & 72.3 \\
\hline Species & \multicolumn{2}{|c|}{$C_{i i}{ }^{5}$} & $\theta_{\mathrm{p}: \mathrm{CIV}}{ }^{6}$ & \multicolumn{2}{|c|}{$\kappa_{\mathrm{p}: \mathrm{CIV}^{7}}$} & Predicted \\
\hline (Symmetry) & \multicolumn{2}{|c|}{$\left(\AA\right.$ mdyn $\left.^{-1}\right)$} & $\left({ }^{\circ}\right)$ & \multicolumn{2}{|c|}{$\left(\mathrm{au}^{-1}\right)$} & nature \\
\hline $\mathrm{Br}_{4}\left(C_{\mathrm{s}}-\mathrm{L}_{1}\right)$ & \multicolumn{2}{|c|}{15.311} & 87.8 & \multicolumn{2}{|c|}{121.2} & $p-\mathrm{CS} / \mathrm{vdW}^{8}$ \\
\hline $\mathrm{Br}_{6}\left(\mathrm{C}_{\mathrm{s}}-\mathrm{L}_{2}\right)$ & \multicolumn{2}{|c|}{14.984} & 89.0 & \multicolumn{2}{|c|}{124.9} & $p-\mathrm{CS} / \mathrm{vdW}^{8}$ \\
\hline $\mathrm{Br}_{6}\left(\mathrm{C}_{\mathrm{s}}-\mathrm{L}_{2}\right)$ & \multicolumn{2}{|c|}{14.114} & 90.6 & \multicolumn{2}{|c|}{127.3} & $p-\mathrm{CS} / t-\mathrm{HB}^{9}$ \\
\hline $\mathrm{Br}_{8}\left(C_{\mathrm{s}}-\mathrm{L}_{3}\right)$ & \multicolumn{2}{|c|}{14.826} & 89.2 & \multicolumn{2}{|c|}{125.0} & $p$-CS/vdW 8 \\
\hline $\mathrm{Br}_{8}\left(\mathrm{C}_{\mathrm{s}}-\mathrm{L}_{3}\right)$ & \multicolumn{2}{|c|}{13.590} & 92.2 & & & $p-\mathrm{CS} / t-\mathrm{HB}^{9}$ \\
\hline $\mathrm{Br}_{8}\left(\mathrm{C}_{\mathrm{s}}-\mathrm{L}_{3}\right)$ & & & & & & $p-\mathrm{CS} / t-\mathrm{HB}^{9}$ \\
\hline $\mathrm{Br}_{10}\left(\mathrm{C}_{\mathrm{s}}-\mathrm{L}_{4}\right)$ & & & & & & $p-\mathrm{CS} / \mathrm{vdW}^{8}$ \\
\hline $\mathrm{Br}_{10}\left(\mathrm{C}_{\mathrm{s}}-\mathrm{L}_{4}\right)$ & & & & & & $p-\mathrm{CS} / t-\mathrm{HB}^{9}$ \\
\hline $\mathrm{Br}_{10}\left(\mathrm{C}_{\mathrm{s}}-\mathrm{L}_{4}\right)$ & & & & & & $p-\mathrm{CS} / t-\mathrm{HB}^{9}$ \\
\hline $\mathrm{Br}_{10}\left(\mathrm{C}_{\mathrm{s}}-\mathrm{L}_{4}\right)$ & & & & & & $p-\mathrm{CS} / t-\mathrm{HB}^{9}$ \\
\hline $\mathrm{Br}_{12}\left(\mathrm{C}_{\mathrm{s}}-\mathrm{L}_{5}\right)$ & & & & & & $p-\mathrm{CS} / \mathrm{vdW}^{8}$ \\
\hline $\mathrm{Br}_{12}\left(\mathrm{C}_{\mathrm{s}}-\mathrm{L}_{5}\right)$ & & & & & & $p-\mathrm{CS} / t-\mathrm{HB}^{9}$ \\
\hline $\mathrm{Br}_{12}\left(\mathrm{C}_{\mathrm{s}}-\mathrm{L}_{5}\right)$ & & & & & & $p-\mathrm{CS} / t-\mathrm{HB}^{9}$ \\
\hline $\mathrm{Br}_{12}\left(\mathrm{C}_{\mathrm{s}}-\mathrm{L}_{5}\right)$ & & & & & & $p-\mathrm{CS} / t-\mathrm{HB}^{9}$ \\
\hline $\mathrm{Br}_{12}\left(\mathrm{C}_{\mathrm{s}}-\mathrm{L}_{5}\right)$ & & & & & & $p-\mathrm{CS} / t-\mathrm{HB}^{9}$ \\
\hline $\mathrm{Br}_{6}\left(C_{2}\right)$ & & & & & & $p-\mathrm{CS} / \mathrm{vdW}^{8}$ \\
\hline $\mathrm{Br}_{10}\left(C_{2}\right)$ & & & & & & $p-\mathrm{CS} / t-\mathrm{HB}^{9}$ \\
\hline $\mathrm{Br}_{10}\left(C_{2}\right)$ & & & & & & $p-\mathrm{CS} / \mathrm{vdW}^{8}$ \\
\hline
\end{tabular}


Table 2. The $\rho_{\mathrm{b}}\left(r_{\mathrm{c}}\right), H_{\mathrm{b}}\left(r_{\mathrm{c}}\right)-V_{\mathrm{b}}\left(r_{\mathrm{c}}\right) / 2\left(=\left(\hbar^{2} / 8 m\right) \nabla^{2} \rho_{\mathrm{b}}\left(r_{\mathrm{c}}\right)\right)$, and $H_{\mathrm{b}}\left(r_{\mathrm{c}}\right)$ values and QTAIM-DFA parameters for Br- $*-\mathrm{Br}$ at BCPs in $\mathrm{Br}_{4}-\mathrm{Br}_{12}$, other than the $C_{\mathrm{s}}-\mathrm{L}_{m}$ structures, evaluated with MP2/6-311+G(3df) ${ }^{1}$.

\begin{tabular}{|c|c|c|c|c|c|c|}
\hline Species & BCP on & $\rho_{\mathrm{b}}\left(r_{\mathrm{c}}\right)$ & $c \nabla^{2} \rho_{\mathrm{b}}\left(r_{\mathrm{c}}\right)^{2}$ & $H_{\mathrm{b}}\left(r_{\mathrm{c}}\right)$ & $R^{3}$ & $\theta^{4}$ \\
\hline (Symmetry) & & $(\mathrm{au})$ & (au) & (au) & (au) & $\left(^{\circ}\right)$ \\
\hline $\mathrm{Br}_{4}\left(C_{2 h}\right)$ & $r_{2}$ & 0.0055 & 0.0022 & 0.0009 & 0.0024 & 67.2 \\
\hline $\mathrm{Br}_{4}\left(D_{2 \mathrm{~d}}\right)$ & $r_{2}$ & 0.0042 & 0.0017 & 0.0007 & 0.0018 & 66.0 \\
\hline $\mathrm{Br}_{6}\left(C_{\left.3 h^{-}-c\right)}\right.$ & $r_{2}$ & 0.0092 & 0.0038 & 0.0013 & 0.0040 & 70.7 \\
\hline $\mathrm{Br}_{8}\left(S_{4}\right)$ & $r_{2}$ & 0.0128 & 0.0051 & 0.0014 & 0.0053 & 74.8 \\
\hline $\mathrm{Br}_{8}\left(S_{4}-\mathrm{Wm}\right)^{5}$ & $r_{2}$ & 0.0136 & 0.0054 & 0.0013 & 0.0056 & 76.0 \\
\hline $\mathrm{Br}_{8}\left(S_{4}-\mathrm{Wm}\right)^{5}$ & $r_{3}$ & 0.0038 & 0.0015 & 0.0007 & 0.0016 & 66.0 \\
\hline $\mathrm{Br}_{10}\left(C_{2}-c\right)$ & $r_{2}$ & 0.0087 & 0.0035 & 0.0012 & 0.0037 & 70.5 \\
\hline $\mathrm{Br}_{10}\left(C_{2}-c\right)$ & $r_{4}$ & 0.0097 & 0.0040 & 0.0014 & 0.0042 & 71.3 \\
\hline $\mathrm{Br}_{10}\left(C_{2}-c\right)$ & $r_{6}$ & 0.0110 & 0.0044 & 0.0014 & 0.0046 & 73.0 \\
\hline $\mathrm{Br}_{10}\left(C_{2}-c\right)$ & $r_{7}$ & 0.0049 & 0.0019 & 0.0008 & 0.0021 & 66.2 \\
\hline $\mathrm{Br}_{10}\left(C_{2}-c\right)$ & $r_{8}$ & 0.0049 & 0.0018 & 0.0008 & 0.0020 & 66.6 \\
\hline $\mathrm{Br}_{12}\left(C_{\mathrm{i}}\right)$ & $r_{2}$ & 0.0129 & 0.0052 & 0.0014 & 0.0054 & 75.0 \\
\hline $\operatorname{Br}_{12}\left(C_{\mathrm{i}}\right)$ & $r_{4}$ & 0.0129 & 0.0052 & 0.0014 & 0.0054 & 75.0 \\
\hline Species & \multicolumn{2}{|c|}{$C_{i i}{ }^{6}$} & $\theta_{\mathrm{p}: \mathrm{CIV}}{ }^{7}$ & \multicolumn{2}{|c|}{$\kappa_{\mathrm{p}: \mathrm{CIV}}{ }^{8}$} & Predicted \\
\hline (Symmetry) & $(\AA \mathrm{mc}$ & \multicolumn{2}{|c|}{$\left({ }^{\circ}\right)$} & & \multicolumn{2}{|c|}{ nature } \\
\hline $\mathrm{Br}_{4}\left(C_{2 \mathrm{~h}}\right)$ & & \multicolumn{2}{|c|}{73.6} & & \multicolumn{2}{|c|}{$p-\mathrm{CS} / \mathrm{vdW}^{9}$} \\
\hline $\mathrm{Br}_{4}\left(D_{2 \mathrm{~d}}\right)$ & 40. & \multicolumn{2}{|c|}{69.6} & & \multicolumn{2}{|c|}{$p-\mathrm{CS} / \mathrm{vdW}^{9}$} \\
\hline $\mathrm{Br}_{6}\left(C_{3 h^{-c}}\right)$ & 25. & \multicolumn{2}{|c|}{83.3} & & \multicolumn{2}{|c|}{$p-\mathrm{CS} / \mathrm{vdW}^{9}$} \\
\hline $\mathrm{Br}_{8}\left(S_{4}\right)$ & 13. & \multicolumn{2}{|c|}{93.5} & & \multicolumn{2}{|c|}{$p-\mathrm{CS} / t-\mathrm{HB}^{10}$} \\
\hline $\mathrm{Br}_{8}\left(S_{4}-\mathrm{Wm}\right)^{5}$ & 11. & \multicolumn{2}{|c|}{95.3} & & \multicolumn{2}{|c|}{$p-\mathrm{CS} / t-\mathrm{HB}{ }^{10}$} \\
\hline $\mathrm{Br}_{8}\left(S_{4}-\mathrm{Wm}\right)^{5}$ & 52. & \multicolumn{2}{|c|}{67.5} & & \multicolumn{2}{|c|}{$p-\mathrm{CS} / \mathrm{vdW}^{9}$} \\
\hline $\mathrm{Br}_{10}\left(C_{2}-c\right)$ & 34. & \multicolumn{2}{|c|}{81.3} & & \multicolumn{2}{|c|}{$p$-CS/vdW 9} \\
\hline $\mathrm{Br}_{10}\left(C_{2}-c\right)$ & 23. & \multicolumn{2}{|c|}{84.7} & & \multicolumn{2}{|c|}{$p-\mathrm{CS} / \mathrm{vdW}^{9}$} \\
\hline $\mathrm{Br}_{10}\left(C_{2}-c\right)$ & 20. & \multicolumn{2}{|c|}{87.6} & & \multicolumn{2}{|c|}{$p-\mathrm{CS} / \mathrm{vdW}^{9}$} \\
\hline $\mathrm{Br}_{10}\left(C_{2}-c\right)$ & 29. & \multicolumn{2}{|c|}{71.5} & & \multicolumn{2}{|c|}{$p-\mathrm{CS} / \mathrm{vdW}^{9}$} \\
\hline $\mathrm{Br}_{10}\left(C_{2}-c\right)$ & 37. & \multicolumn{2}{|c|}{71.8} & & \multicolumn{2}{|c|}{$p$-CS/vdW 9} \\
\hline $\mathrm{Br}_{12}\left(C_{\mathrm{i}}\right)$ & 13. & \multicolumn{2}{|c|}{93.7} & & \multicolumn{2}{|c|}{$p-\mathrm{CS} / t-\mathrm{HB}^{10}$} \\
\hline $\mathrm{Br}_{12}\left(C_{\mathrm{i}}\right)$ & 13. & \multicolumn{2}{|c|}{93.7} & & & $\mathrm{~B}^{10}$ \\
\hline
\end{tabular}

${ }^{1}$ The interactions in minima are shown. ${ }^{2} \mathrm{c} \nabla^{2} \rho_{\mathrm{b}}\left(r_{\mathrm{c}}\right)=H_{\mathrm{b}}\left(r_{\mathrm{c}}\right)-V_{\mathrm{b}}\left(r_{\mathrm{c}}\right) / 2$, where $\left.c=\hbar^{2} / 8 m .{ }^{3} R=\left[H_{\mathrm{b}}\left(r_{\mathrm{c}}\right)-V_{\mathrm{b}}\left(r_{\mathrm{c}}\right) / 2\right)^{2}+H_{\mathrm{b}}\left(r_{\mathrm{c}}\right)^{2}\right] 1 / 2 .{ }^{4}$ $\theta=90^{\circ}-\tan ^{-1}\left[H_{\mathrm{b}}\left(r_{\mathrm{c}}\right) /\left(H_{\mathrm{b}}\left(r_{\mathrm{c}}\right)-V_{\mathrm{b}}\left(r_{\mathrm{c}}\right) / 2\right)\right] .{ }^{5}$ Image from windmill. ${ }^{6}$ Defined in Equation (R1) in the text. ${ }^{7} \theta_{\mathrm{p}}=90^{\circ}-\tan ^{-1}(\mathrm{~d} y / \mathrm{d} x)$, where $(x, y)=\left(H_{\mathrm{b}}\left(r_{\mathrm{c}}\right)-V_{\mathrm{b}}\left(r_{\mathrm{c}}\right) / 2, H_{\mathrm{b}}\left(r_{\mathrm{c}}\right)\right) .{ }^{8} \kappa_{\mathrm{p}}=\left|\mathrm{d}^{2} y / \mathrm{d} x^{2}\right| /\left[1+(\mathrm{d} y / \mathrm{d} x)^{2}\right]^{3 / 2} .{ }^{9}$ The pure CS interaction of the vdW nature. ${ }^{10}$ The pure CS interaction of the $\mathrm{HB}$ nature without covalency.

(a)

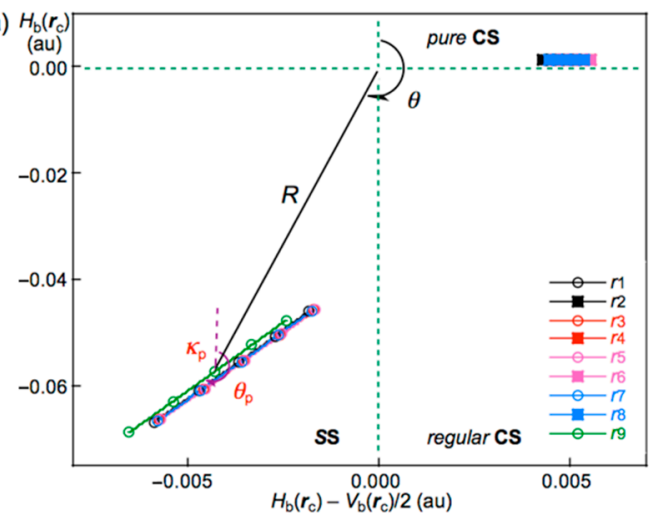

(b)
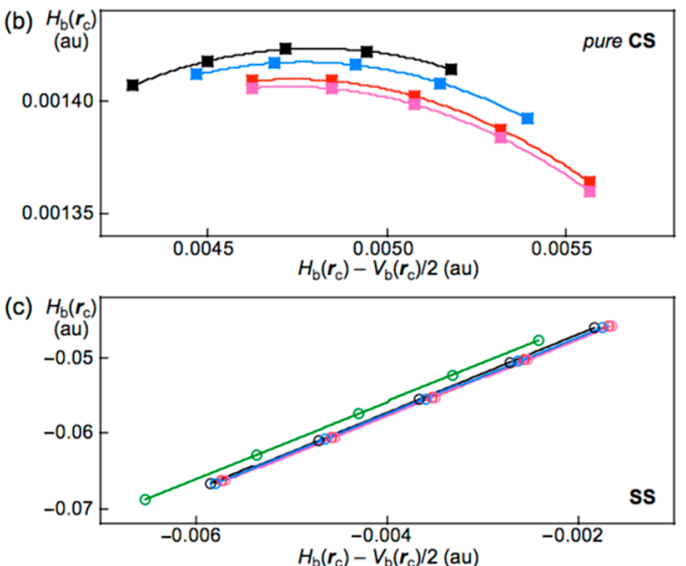

Figure 5. QTAIM-DFA plots $\left(H_{\mathrm{b}}\left(\boldsymbol{r}_{\mathrm{c}}\right)\right.$ versus $\left.H_{\mathrm{b}}\left(\boldsymbol{r}_{\mathrm{c}}\right)-V_{\mathrm{b}}\left(\boldsymbol{r}_{\mathrm{c}}\right) / 2\right)$ for the interactions in $\mathrm{Br}_{10}\left(C_{\mathrm{s}}-\mathrm{L}_{4}\right)$, evaluated with MP2/6$311+\mathrm{G}(3 \mathrm{df})$; (a) whole region, (b) pure CS region, and (c) SS region. Marks and colors are shown in the figure. 
QTAIM-DFA parameters of $(R, \theta)$ and $\left(\theta_{\mathrm{p}}, \kappa_{\mathrm{p}}\right)$ are obtained by analyzing the plots of $H_{\mathrm{b}}\left(\boldsymbol{r}_{\mathrm{c}}\right)$ versus $H_{\mathrm{b}}\left(\boldsymbol{r}_{\mathrm{c}}\right)-V_{\mathrm{b}}\left(\boldsymbol{r}_{\mathrm{c}}\right) / 2$, according to Equations (S3)-(S6). Table 1 collects the QTAIM-DFA parameters for the noncovalent $\mathrm{Br}-*-\mathrm{Br}$ interactions of $\mathrm{Br}_{4}\left(C_{\mathrm{s}}-\mathrm{L}_{1}\right)-\mathrm{Br}_{12}\left(C_{\mathrm{s}^{-}}\right.$$\left.\mathrm{L}_{5}\right), \mathrm{Br}_{6}\left(C_{2}\right)$, and $\mathrm{Br}_{10}\left(C_{2}\right)$ together with the $C_{i i}$ values. Table 2 collects the $(R, \theta)$ and $\left(\theta_{\mathrm{p}}\right.$, $\kappa_{\mathrm{p}}$ ) values for $\mathrm{Br}_{4}-\mathrm{Br}_{12}$, other than those given in Table 1, together with the $C_{i i}$ values. The $(R, \theta)$ and $\left(\theta_{\mathrm{p}}, \kappa_{\mathrm{p}}\right)$ values for the covalent $\mathrm{Br}-*-\mathrm{Br}$ bonds in $\mathrm{Br}_{4}-\mathrm{Br}_{12}$ are collected in Table S4.

\subsection{The Nature of Br-*-Br Interactions in Polybromine Clusters}

The nature of the covalent and noncovalent $\mathrm{Br}-*-\mathrm{Br}$ interactions in $\mathrm{Br}_{2}-\mathrm{Br}_{12}$ is discussed on the basis of the $\left(R, \theta, \theta_{\mathrm{p}}\right)$ values, employing standard values as a reference (see Scheme SA3).

It is instructive to survey the criteria shown in Scheme SA3 before detailed discussion. The criteria tell us that $180^{\circ}<\theta\left(H_{\mathrm{b}}\left(\boldsymbol{r}_{\mathrm{c}}\right)-V_{\mathrm{b}}\left(\boldsymbol{r}_{\mathrm{c}}\right) / 2<0\right)$ for the SS interactions and $\theta<180^{\circ}$ $\left(H_{\mathrm{b}}\left(\boldsymbol{r}_{\mathrm{c}}\right)-V_{\mathrm{b}}\left(\boldsymbol{r}_{\mathrm{c}}\right) / 2>0\right)$ for the CS interactions. The CS interactions are subdivided into pure CS interactions ( $p$-CS) of $45^{\circ}<\theta<90^{\circ}\left(H_{\mathrm{b}}\left(r_{\mathrm{c}}\right)>0\right)$ and regular CS interactions $(r-\mathrm{CS})$ of $90^{\circ}<\theta<180^{\circ}\left(H_{\mathrm{b}}\left(r_{\mathrm{c}}\right)<0\right)$. The $\theta_{\mathrm{p}}$ value predicts the character of interactions. In the pure CS region of $45^{\circ}<\theta<90^{\circ}$, the character of interactions will be the vdW type for $45^{\circ}$ $<\theta_{\mathrm{p}}<90^{\circ}$ and the typical-HB type with no covalency $\left(t-\mathrm{HB}_{\mathrm{nc}}\right)$ for $90^{\circ}<\theta_{\mathrm{p}}<125^{\circ}$, where $\theta_{\mathrm{p}}=125^{\circ}$ approximately corresponds to $\theta=90^{\circ}$. The classical chemical covalent bonds of SS $\left(180^{\circ}<\theta\right)$ will be strong when $R>0.15$ au (Cov-s: strong covalent bonds), whereas they will be weak for $R<0.15$ au (Cov-w: weak covalent bonds).

The $\left(R, \theta, \theta_{\mathrm{p}}\right)$ values are $\left(0.0576 \mathrm{au}, 184.3^{\circ}, 190.9^{\circ}\right)$ for the original $\mathrm{Br}_{2}$ if evaluated with MP2/6-311+G(3df). Therefore, the nature of the $\mathrm{Br}-*-\mathrm{Br}$ bond in $\mathrm{Br}_{2}$ is classified by the SS interactions $\left(\theta>180^{\circ}\right)$ and characterized to have a Cov-w nature $\left(\theta_{\mathrm{p}}>180^{\circ}\right.$ and $R<$ $0.15 \mathrm{au})$. The nature is denoted by SS/Cov-w. The $\left(R, \theta, \theta_{\mathrm{p}}\right)$ values for the covalent $\mathrm{Br}-*-\mathrm{Br}$ bonds in $\mathrm{Br}_{4}-\mathrm{Br}_{12}$ are $\left(0.0472-0.0578 \mathrm{au}, 182.0-184.4^{\circ}, 190.4-192.1^{\circ}\right)$; therefore, their nature is predicted to be SS/Cov-w. The nature of the covalent $\mathrm{Br}-*-\mathrm{Br}$ bonds seems unchanged in the formation of the clusters $[53,54]$. The noncovalent $\mathrm{Br}-*-\mathrm{Br}$ interactions in $\mathrm{Br}_{4}-\mathrm{Br}_{12}$ are all classified by pure CS interactions since $\theta \leq 76^{\circ}\left(<<90^{\circ}\right)[53,54]$. The $\theta_{\mathrm{p}}$ values in the $C_{\mathrm{s}}-\mathrm{L}_{m}$ clusters change systematically. The $\theta_{\mathrm{p}}$ values for $r_{2}$ in $\mathrm{Br}_{2 k}\left(C_{\mathrm{s}}-\mathrm{L}_{m}\right)(k=2-6)$ are predicted to be in the range of $89.1^{\circ} \leq \theta_{\mathrm{p}} \leq 89.6^{\circ}$, with $\theta_{\mathrm{p}}=87.9^{\circ}$ for $\mathrm{Br}_{4}\left(C_{\mathrm{s}}-\mathrm{L}_{1}\right)$.

However, the values for $r_{n-2}$ in $\mathrm{Br}_{2 k}\left(C_{\mathrm{s}}-\mathrm{L}_{m}\right)(k=2-6)$ are in the range of $90.6^{\circ} \leq \theta_{\mathrm{p}}$ $\leq 91.2^{\circ}$ and the values for noncovalent interactions, other than edge positions, are in the range of $92.1^{\circ} \leq \theta_{\mathrm{p}} \leq 93.0^{\circ}$. Namely, the noncovalent $\mathrm{Br}-*-\mathrm{Br}$ interactions are predicted to have the vdW nature ( $p$-CS/vdW) for $r_{2}$, while the interactions other than $r_{2}$ are predicted to have the $t-\mathrm{HB}_{\mathrm{nc}}$ nature $\left(p-\mathrm{CS} / t-\mathrm{HB}_{\mathrm{nc}}\right)$ since $\theta_{\mathrm{p}}>90^{\circ}$. The $\theta_{\mathrm{p}}$ values of $r_{2}$ for the $C_{\mathrm{s}}-\mathrm{L}_{m}$ clusters will be less than $90^{\circ}$, irrespective of the angles between $r_{1}$ and $r_{2}$, which are close to $180^{\circ}$. The $\theta_{\mathrm{p}}$ values will be larger than $90^{\circ}$ for all noncovalent interactions other than $r_{2}$. Table 1 contains the data for $\mathrm{Br}_{10}\left(C_{2}\right)$, of which $\theta_{\mathrm{p}}=90.4^{\circ}\left(>90^{\circ}\right)$ for $r_{2}$ and $\theta_{\mathrm{p}}=87.1^{\circ}\left(<90^{\circ}\right)$ for $r_{4}$, although $\mathrm{Br}_{10}\left(C_{2}\right)$ is not the $C_{\mathrm{s}}-\mathrm{L}_{m}$ type. The results for $r_{2}$ seem reasonable based on the structure (cf. Figure 3), while those for $r_{4}$ would be complex. Table 1 summarizes the predicted nature.

In the case of the noncovalent $\mathrm{Br}-*-\mathrm{Br}$ interactions in $\mathrm{Br}_{4}-\mathrm{Br}_{12}$, other than the $\mathrm{C}_{\mathrm{s}}-\mathrm{L}_{m}$ type clusters, $\theta_{\mathrm{p}}>90^{\circ}$ for $r_{2}$ in $\mathrm{Br}_{8}\left(S_{4}\right)\left(\theta_{\mathrm{p}}=93.4^{\circ}\right)$ and $\mathrm{Br}_{8}\left(S_{4}-\mathrm{Wm}\right)\left(\theta_{\mathrm{p}}=94.8^{\circ}\right)$ and for $r_{2}$, $r_{4}$, and $r_{6}$ in $\operatorname{Br}_{12}\left(C_{\mathrm{i}}\right)\left(93.4^{\circ} \leq \theta_{\mathrm{p}} \leq 93.7^{\circ}\right)$. The interactions would have the $t-\mathrm{HB}_{\mathrm{nc}}$ nature $\left(p-\mathrm{CS} / t-\mathrm{HB}_{\mathrm{nc}}\right)$. Very weak noncovalent $\mathrm{Br}-*-\mathrm{Br}$ interactions are also detected. The ranges of $64.2^{\circ} \leq \theta \leq 66.6^{\circ}$ and $66.2^{\circ} \leq \theta_{\mathrm{p}} \leq 71.2^{\circ}$ are predicted for $r_{2}$ and $r_{3}$ in $\mathrm{Br}_{4}\left(C_{2 \mathrm{~h}}\right), r_{2}$ in $\mathrm{Br}_{4}$ $\left(C_{2 \mathrm{v}}\right), r_{3}$ in $\mathrm{Br}_{8}\left(S_{4}-\mathrm{Wm}\right)$, and $r_{7}$ and $r_{8}$ in $\mathrm{Br}_{10}\left(C_{2}-c\right)$. The results are summarized in Table 2 .

What are the relationships between the QTAIM-DFA parameters for the noncovalent $\mathrm{Br}-*-\mathrm{Br}$ interactions? The $\theta$ and $\theta_{\mathrm{p}}$ values are plotted versus $R$. The plots are shown in Figure S4; they give very good correlations. The $\theta_{\mathrm{p}}$ values are plotted versus $\theta$. The plot is shown in Figure S5; it also gives a very good correlation. Table 3 summarizes the correlations among the QTAIM-DFA parameters. 
Table 3. Correlations in the plots ${ }^{1}$.

\begin{tabular}{cccccc}
\hline Entry & Correlation & $\boldsymbol{a}$ & $\boldsymbol{b}$ & $\boldsymbol{R}_{\mathbf{c}}{ }^{\mathbf{2}}$ & $\boldsymbol{n}$ \\
\hline 1 & $\Delta E_{\text {ZP vs. } \Delta E_{\mathrm{ES}}}$ & 0.940 & 0.129 & 0.9999 & $20^{2}$ \\
2 & $\theta$ vs. $R$ & 2595.6 & 60.70 & 0.979 & 33 \\
3 & $\theta_{\mathrm{p}}$ vs. $R$ & 6449.1 & 58.19 & 0.989 & 33 \\
4 & $\theta_{\mathrm{p}}$ vs. $\theta$ & 2.67 & -106.26 & 0.992 & $31^{3}$ \\
5 & $E(2)$ vs. $C_{i i}-1$ & 535.5 & -18.22 & 0.997 & $15^{4}$ \\
6 & $E(2)$ vs. $R$ & 9760.9 & -29.92 & 0.983 & $15^{4}$ \\
7 & $E(2)$ vs $\theta$ & 2.446 & -160.88 & 0.996 & $15^{4}$ \\
8 & $E(2)$ vs. $\theta_{\mathrm{p}}$ & 1.067 & 77.17 & 0.999 & $15^{4}$ \\
\hline
\end{tabular}

${ }^{1}$ The constants $\left(a, b, R_{\mathrm{c}}{ }^{2}\right)$ are the correlation constant, the $y$-intercept, and the square of the correlation coefficient, respectively, in $y=a x+b .{ }^{2}$ Containing TS species. ${ }^{3}$ Neglecting the data of $r_{2}$ and $r_{3}$ in $\mathrm{Br}_{4}\left(C_{2 \mathrm{~h}}\right) .{ }^{4}$ For the noncovalent $\mathrm{Br}-*-\mathrm{Br}$ interactions in $\mathrm{Br}_{4}\left(C_{\mathrm{s}}-\mathrm{L}_{1}\right)-\mathrm{Br}_{12}\left(C_{\mathrm{s}}-\mathrm{L}_{5}\right)$.

To further examine the behavior of noncovalent $\mathrm{Br}-*-\mathrm{Br}$ interactions, $\mathrm{NBO}$ analysis is applied to the interactions.

\subsection{NBO Analysis for $B r-*-B r$ of $B r_{4}\left(C_{s}-L_{1}\right)-B r_{12}\left(C_{s}-L_{5}\right)$}

The noncovalent $\mathrm{Br}-*-\mathrm{Br}$ interactions in $\mathrm{Br}_{4}\left(C_{\mathrm{s}}-\mathrm{L}_{1}\right)-\mathrm{Br}_{12}\left(C_{\mathrm{s}}-\mathrm{L}_{5}\right)$ are characterized by $\sigma(3 \mathrm{c}-4 \mathrm{e})$ of the $n(\mathrm{Br}) \rightarrow \sigma^{*}(\mathrm{Br}-\mathrm{Br})$ type. NBO analysis [56] was applied to the $n(\mathrm{Br}) \rightarrow \sigma^{*}(\mathrm{Br}-$ $\mathrm{Br})$ interactions with MP2/6-311+G(3df). For each donor NBO (i) and acceptor NBO (j), the stabilization energy $E(2)$ is calculated based on the second-order perturbation theory in NBO. The $E(2)$ values are calculated according to Equation (4), where $q_{i}$ is the donor orbital occupancy, $\varepsilon_{i}, \varepsilon_{j}$ are diagonal elements (orbital energies), and $F(i, j)$ is the off-diagonal NBO Fock matrix element. The values are obtained separately by the contributions from $n_{\mathrm{s}}(\mathrm{Br}) \rightarrow \sigma^{*}(\mathrm{Br}-\mathrm{Br})$ and $n_{\mathrm{p}}(\mathrm{Br}) \rightarrow \sigma^{*}(\mathrm{Br}-\mathrm{Br})$, which are summarized in Table S5. The total values corresponding to $n_{\mathrm{s}+\mathrm{p}}(\mathrm{Br}) \rightarrow \sigma^{*}(\mathrm{Br}-\mathrm{Br})\left(=n_{\mathrm{s}}(\mathrm{Br}) \rightarrow \sigma^{*}(\mathrm{Br}-\mathrm{Br})+n_{\mathrm{p}}(\mathrm{Br}) \rightarrow \sigma^{*}(\mathrm{Br}-\mathrm{Br})\right)$ were calculated, which are also summarized in Table S5. The total values are employed for the discussion.

$$
E(2)=q_{i} \times F(i, j)^{2} /\left(\varepsilon_{j}-\varepsilon_{i}\right)
$$

Figure 6 shows the plots of $E(2)$ and $\theta_{\mathrm{p}}$ for the noncovalent $\mathrm{Br}-*-\mathrm{Br}$ interactions in $\mathrm{Br}_{4}$ $\left(C_{\mathrm{S}}-\mathrm{L}_{1}\right)-\mathrm{Br}_{12}\left(C_{\mathrm{s}}-\mathrm{L}_{5}\right)$. The values become larger in the order of $\mathrm{P}\left(r_{2}: \mathrm{Br}_{4}\left(C_{\mathrm{s}}-\mathrm{L}_{1}\right)\right)<\mathrm{P}\left(r_{2}: \mathrm{Br}_{6}\right.$ $\left.\left(C_{\mathrm{s}}-\mathrm{L}_{2}\right)-\mathrm{Br}_{12}\left(C_{\mathrm{s}}-\mathrm{L}_{5}\right)\right)<\mathrm{P}\left(r_{\omega}: \mathrm{Br}_{6}\left(C_{\mathrm{s}}-\mathrm{L}_{2}\right)-\mathrm{Br}_{12}\left(C_{\mathrm{s}}-\mathrm{L}_{5}\right)\right)<\mathrm{P}\left(r_{\text {in }}: \mathrm{Br}_{6}\left(C_{\mathrm{s}}-\mathrm{L}_{2}\right)-\mathrm{Br}_{12}\left(C_{\mathrm{s}}-\mathrm{L}_{5}\right)\right)$, where P means $E(2)$ or $\theta_{\mathrm{p}}$, while $r_{\omega}$ and $r_{\text {in }}$ stand for the last end and the inside noncovalent interactions, respectively, in the sequence (see Figures 2 and 3). The values for $P=E(2)$ are as follows: $E(2)=16.6 \mathrm{~kJ} \mathrm{~mol}^{-1}$ for $r_{2}$ in $\mathrm{Br}_{4}\left(C_{\mathrm{s}}-\mathrm{L}_{1}\right)<17.7 \leq E(2) \leq 18.2 \mathrm{~kJ} \mathrm{~mol}^{-1}$ for $r_{2}$ in $\mathrm{Br}_{6}\left(C_{\mathrm{s}}-\mathrm{L}_{2}\right)-\mathrm{Br}_{12}\left(C_{\mathrm{s}}-\mathrm{L}_{5}\right)<19.5 \leq E(2) \leq 20.0 \mathrm{~kJ} \mathrm{~mol}^{-1}$ for $r_{\omega}$ in $\mathrm{Br}_{6}\left(C_{\mathrm{s}}-\mathrm{L}_{2}\right)-\mathrm{Br}_{12}\left(C_{\mathrm{s}}-\mathrm{L}_{5}\right)<$ $21.2 \leq E(2) \leq 22.0 \mathrm{~kJ} \mathrm{~mol}^{-1}$ for $r_{\text {in }}$ in $\mathrm{Br}_{8}\left(C_{\mathrm{s}}-\mathrm{L}_{3}\right)-\mathrm{Br}_{12}\left(C_{\mathrm{s}}-\mathrm{L}_{5}\right)$.

Relations between $E(2)$ and $C_{i i}$ were also examined for noncovalent $\mathrm{Br}-*-\mathrm{Br}$ interactions in $\mathrm{Br}_{4}\left(C_{\mathrm{s}}-\mathrm{L}_{1}\right)-\mathrm{Br}_{12}\left(C_{\mathrm{s}}-\mathrm{L}_{5}\right)$. The $E(2)$ values were plotted versus $C_{i i}{ }^{-1}$ for the noncovalent interactions. Figure 7 shows the plot. The plot gives a very good correlation, which is shown in Table 3 (Entry 5). The results show that the energies for $\sigma(3 c-4 e)$ of the $n_{\mathrm{p}}(\mathrm{Br}) \rightarrow \sigma^{*}(\mathrm{Br}-\mathrm{Br})$ type in $\mathrm{Br}_{4}\left(C_{\mathrm{s}}-\mathrm{L}_{1}\right)-\mathrm{Br}_{12}\left(C_{\mathrm{s}}-\mathrm{L}_{5}\right)$ are well evaluated, not only by $E(2)$ but also by $C_{i i}{ }^{-1}$. Similar relations would be essentially observed for the interactions in the nonlinear clusters; however, the analyses will be much complex due to the unsuitable structures for the NBO analysis, such as the deviations in the interaction angles expected for $\mathrm{Br}_{3}$ $\sigma(3 c-4 e)$, the mutual interactions between $\mathrm{Br}_{3} \sigma(3 c-4 e)$, and /or the steric effect from other bonds and interactions, placed proximity in space. The $E(2)$ values for $\mathrm{Br}_{4}\left(C_{\mathrm{S}}-\mathrm{L}_{1}\right)-\mathrm{Br}_{12}$ $\left(C_{\mathrm{s}}-\mathrm{L}_{5}\right)$ were also plotted versus $R, \theta$, and $\theta_{\mathrm{p}}$, shown in Figures S6-S8, respectively. The plots give very good correlations, which are given in Table 3 (Entries 6-8). 


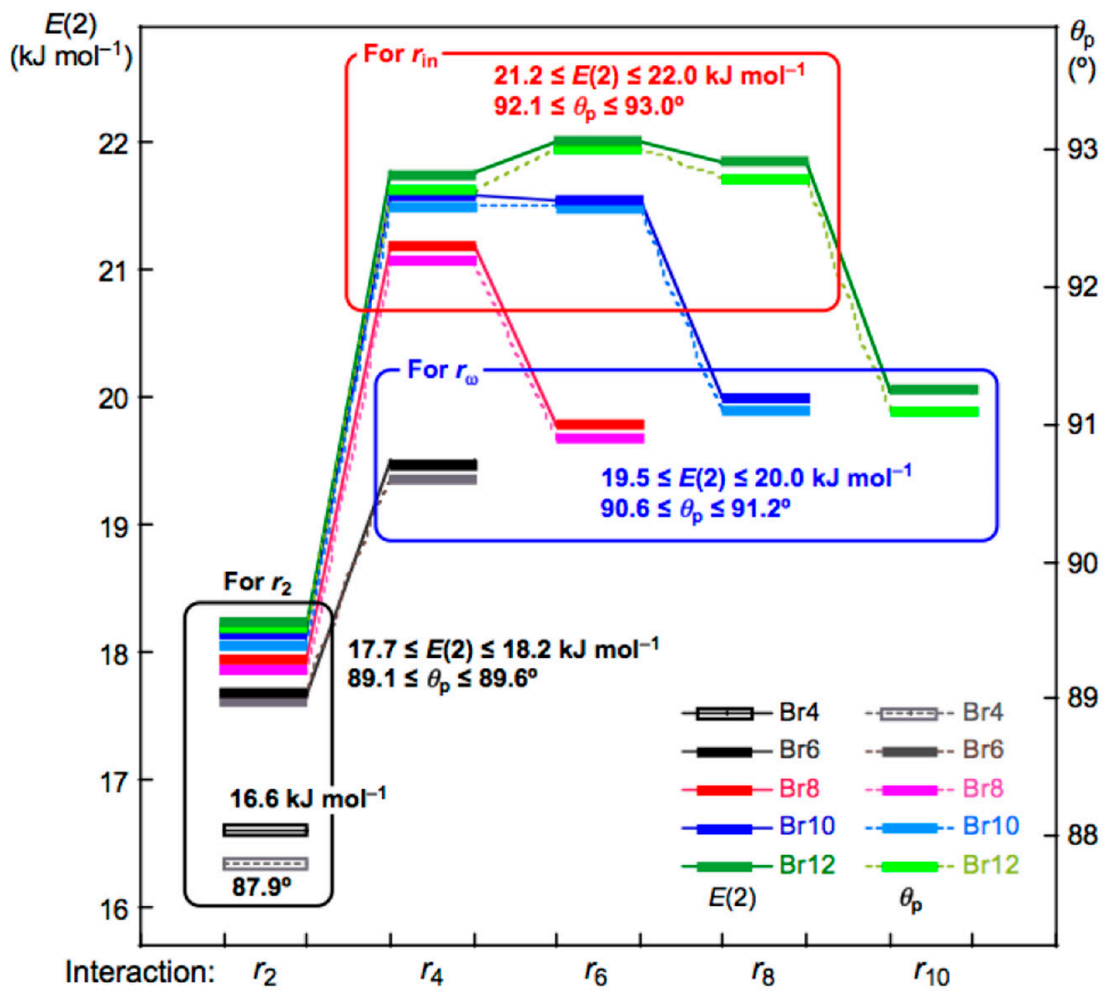

Figure 6. Plots of $\theta_{\mathrm{p}}$ and $E(2)$ for the noncovalent $\mathrm{Br}-*-\mathrm{Br}$ interactions in $\mathrm{Br}_{4}\left(C_{\mathrm{s}}-\mathrm{L}_{1}\right)-\mathrm{Br}_{12}\left(C_{\mathrm{s}}-\mathrm{L}_{5}\right)$. Colors are shown in the figure.

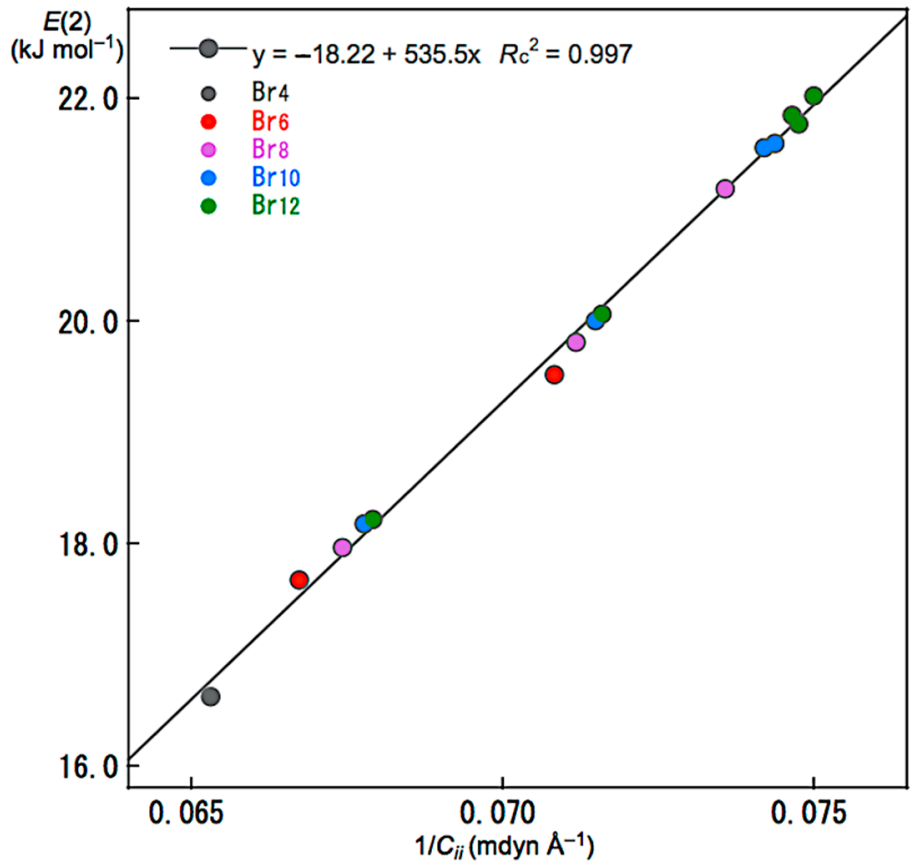

Figure 7. Plot of $E(2)$ versus $1 / C_{i i}$ for the noncovalent $\mathrm{Br}-*-\mathrm{Br}$ interactions in $\mathrm{Br}_{4}\left(C_{\mathrm{s}}-\mathrm{L}_{1}\right)-\mathrm{Br}_{12}\left(C_{\mathrm{s}}-\mathrm{L}_{5}\right)$.

3.6. MO Descriptions for Noncovalent $\mathrm{Br}-*-\mathrm{Br}$ Interactions in $\mathrm{Br}_{4}$

As discussed above, $\mathrm{Br}_{3} \sigma(3 c-4 \mathrm{e})$ of the $n_{\mathrm{p}}(\mathrm{Br}) \rightarrow \sigma^{*}(\mathrm{Br}-\mathrm{Br})$ type plays an important role in the formation of $\mathrm{Br}_{4}\left(C_{\mathrm{s}}-\mathrm{L}_{1}\right)-\mathrm{Br}_{12}\left(C_{\mathrm{s}}-\mathrm{L}_{5}\right)$. However, there must exist some interactions, other than $\mathrm{Br}_{3} \sigma(3 \mathrm{c}-4 \mathrm{e})$, to stabilize the clusters. The $\Delta E_{\mathrm{ES}}$ values for $\mathrm{Br}_{4}\left(C_{2 \mathrm{~h}}\right)$ $\left(-8.0 \mathrm{~kJ} \mathrm{~mol}^{-1}\right)$ and $\mathrm{Br}_{4}\left(D_{2 \mathrm{~d}}\right)\left(-9.1 \mathrm{~kJ} \mathrm{~mol}^{-1}\right)$ are not so different from that for $\mathrm{Br}_{4}\left(C_{\mathrm{s}}-\mathrm{L}_{1}\right)$ $\left(-10.7 \mathrm{~kJ} \mathrm{~mol}^{-1}\right)$. However, $\mathrm{Br}_{4}\left(C_{2 \mathrm{~h}}\right)$ and $\mathrm{Br}_{4}\left(D_{2 \mathrm{~d}}\right)$ must consist of interactions other than 
$\sigma(3 \mathrm{c}-4 \mathrm{e})$. Indeed, $\mathrm{Br}_{3} \sigma(3 \mathrm{c}-4 \mathrm{e})$ of the $n(\mathrm{Br}) \rightarrow \sigma^{*}(\mathrm{Br}-\mathrm{Br})$ type contributes to stabilizing $\mathrm{Br}_{4}$ $\left(C_{\mathrm{s}}-\mathrm{L}_{1}\right)$, but $\mathrm{Br}_{4}\left(C_{2 \mathrm{~h}}\right)$ and $\mathrm{Br}_{4}\left(D_{2 \mathrm{~d}}\right)$ are shown to be stabilized by the $\sigma(\mathrm{Br}-\mathrm{Br}) \rightarrow \sigma^{*} \mathrm{Ry}(\mathrm{Br})$ interaction by NBO, where Ry stands for the Rydberg term, although not shown.

The total energy for a species $(E)$ is given by the sum of the core terms $\left(H_{c}(i)\right)$ over all electrons, $\Sigma_{i}^{n} H_{c}(i)$, and the electron-electron repulsive terms, $\left(\Sigma_{i \neq j}{ }^{n} J_{i j}-\Sigma_{i \neq j, \|}{ }^{n} K_{i j}\right) / 2$, as shown by Equation (5), where $H_{c}(i)$ consists of the kinetic energy and electron-nuclear attractive terms for electron $i$. E contains the nuclear-nuclear repulsive terms, although not clearly shown in Equation (5). As shown in Equation (6), the sum of MO energy for electron $i$, $\varepsilon_{i}$, over all electrons, $\Sigma_{i=1}^{n} \varepsilon_{i}$, will be larger than $E$ by $\left(\Sigma_{i \neq j}{ }^{n} J_{i j}-\Sigma_{i \neq j, \|}{ }^{n} K_{i j}\right) / 2$ since the electron-electron repulsions are doubly counted in Equation (6). Therefore, $\Sigma_{i}{ }^{n} H_{c}(i)$ and $\left(\Sigma_{i \neq j}{ }^{n} J_{i j}-\Sigma_{i \neq j, \|}{ }^{n} K_{i j}\right) / 2$ are given separately by Equations (7) and (8), respectively. The $\varepsilon_{i}$ values for $\mathrm{Br}_{4}\left(C_{2 \mathrm{~h}}\right), \mathrm{Br}_{4}\left(D_{2 \mathrm{~d}}\right)$, and $2 \mathrm{Br}_{2}$, together with $\mathrm{Br}_{4}\left(C_{\mathrm{s}}-\mathrm{L}_{1}\right)$, are collected in Tables S6-S9, respectively, for convenience of discussion. Parameters $(\Delta P)$ in the formation of $\mathrm{Br}_{2 k}$ from the components are evaluated according to Equation (9). The $\Delta \Sigma_{i}{ }^{n} H_{c}(i)$ and $\Delta\left(\sum_{i \neq j}{ }^{n} J_{i j}-\Sigma_{i \neq j, \|}{ }^{n} K_{i j}\right) / 2$ values for the formation of $\mathrm{Br}_{4}\left(C_{2 \mathrm{~h}}\right), \mathrm{Br}_{4}\left(D_{2 \mathrm{~d}}\right)$, and $\mathrm{Br}_{4}\left(C_{\mathrm{s}}-\mathrm{L}_{1}\right)$ are collected in Table S11.

$$
\begin{gathered}
E=\sum_{i}^{n} H_{c}(i)+\left(\sum_{i \neq j}^{n} J_{i j}-\Sigma_{i \neq j, \|}{ }^{n} K_{i j}\right) / 2 \\
\sum_{i=1}^{n} \varepsilon_{i}=\sum_{i}^{n} H_{c}(i)+\left(\sum_{i \neq j}^{n} J_{i j}-\Sigma_{i \neq j, \|}^{n} K_{i j}\right) \\
\sum_{i}^{n} H_{c}(i)=2 E-\sum_{i=1}^{n} \varepsilon_{i} \\
\left(\sum_{i \neq j}^{n} J_{i j}-\Sigma_{i \neq j, \|}{ }^{n} K_{i j}\right) / 2=\Sigma_{i=1}^{n} \varepsilon_{i}-E \\
\Delta P\left(\mathrm{Br}_{2 k}\right)=P\left(\mathrm{Br}_{2 k}\right)-k P\left(\mathrm{Br}_{2}\right)
\end{gathered}
$$

The nature of noncovalent $\mathrm{Br}-\mathrm{Br}$ interactions in $\mathrm{Br}_{4}\left(C_{\mathrm{s}}-\mathrm{L}_{1}\right)$ is examined first. The $\sigma(3 c-4 e)$ character in $\mathrm{Br}_{4}\left(C_{s}-L_{1}\right)$ is confirmed by the natural charge evaluated with NPA $(Q n)$, developed in the formation of $\mathrm{Br}_{4}\left(C_{\mathrm{s}}-\mathrm{L}_{1}\right)$. The evaluated $Q n$ values are $\operatorname{Br}(1$ : $\left.-0.0128\left|\mathrm{e}^{-}\right|\right)-\operatorname{Br}\left(2:-0.0002\left|\mathrm{e}^{-}\right|\right)-\operatorname{Br}\left(3:-0.0010\left|\mathrm{e}^{-}\right|\right)-\operatorname{Br}\left(4: 0.0140\left|\mathrm{e}^{-}\right|\right)$; therefore, $Q n(\operatorname{Br}(4)-\operatorname{Br}(3))$ and $Q n(\operatorname{Br}(2)-\operatorname{Br}(1))$ are $+0.013\left|\mathrm{e}^{-}\right|$and $-0.013\left|\mathrm{e}^{-}\right|$, respectively. Each $\mathrm{MO}$ in $\mathrm{Br}_{4}\left(C_{\mathrm{S}}-\mathrm{L}_{1}\right)$ is almost localized on $\mathrm{Br}(4)-\mathrm{Br}(3)$ or $\mathrm{Br}(2)-\mathrm{Br}(1)$, except for a few cases. MOs in $\mathrm{Br}_{4}\left(C_{\mathrm{s}}-\mathrm{L}_{1}\right)$ must be affected by the local charge. Each MO energy in $\mathrm{Br}_{4}\left(C_{\mathrm{s}}-\mathrm{L}_{1}\right)$ seems higher than the corresponding value of $2 \mathrm{Br}_{2}$ by $10-20 \mathrm{~kJ} \mathrm{~mol}^{-1}$ if the $\mathrm{MO}$ is localized on $\operatorname{Br}(2)-\operatorname{Br}(1)$, lower by $15-25 \mathrm{~kJ} \mathrm{~mol}^{-1}$ on $\operatorname{Br}(3)-\operatorname{Br}(4)$, and slightly lower by $0-5 \mathrm{~kJ} \mathrm{~mol}^{-1}$ if the MO is localized on the whole molecule. We should be careful since it depends on the phase in $\mathrm{MO}$ and the position of the $\mathrm{Br}$ atom(s). Typical cases are shown in Figure S9. In total, $\Delta \Sigma_{i=1}{ }^{n} \varepsilon_{i}$ is evaluated to be $-357.2 \mathrm{~kJ} \mathrm{~mol}^{-1}$ for $\mathrm{Br}_{4}\left(C_{\mathrm{s}}-\mathrm{L}_{1}\right)$. The results show that $\mathrm{Br}_{4}\left(C_{\mathrm{s}}-\mathrm{L}_{1}\right)$ is stabilized in the formation of the dimer from the components through the lowering of $\mathrm{MO}$ energies in total, which is consistent with those evaluated with $\mathrm{NBO}$, as discussed above.

Figure 8 shows the plots of $\Delta \Sigma_{i}^{n} H_{c}(i)$ and $\Delta\left(\sum_{i \neq j}{ }^{n} J_{i j}-\Sigma_{i \neq j, \|^{n}} K_{i j}\right) / 2$ for $\mathrm{Br}_{4}\left(C_{\mathrm{S}}-\mathrm{L}_{1}\right)$, $\mathrm{Br}_{4}\left(C_{2 \mathrm{~h}}\right)$, and $\mathrm{Br}_{4}\left(D_{2 \mathrm{~d}}\right)$, together with $\Delta E_{\mathrm{ES}}$ and $\Delta \Sigma_{i=1}{ }^{n} \varepsilon_{i}$. In the case of $\mathrm{Br}_{4}\left(C_{\mathrm{S}}-\mathrm{L}_{1}\right)$, $\Delta \Sigma_{i}^{n} H_{c}(i)$ and $\Delta\left(\Sigma_{i \neq j}{ }^{n} J_{i j}-\Sigma_{i \neq j, \|}{ }^{n} K_{i j}\right) / 2$ are evaluated to be 335.7 and $-346.4 \mathrm{~kJ} \mathrm{~mol}^{-1}$, respectively, which stabilizes $\mathrm{Br}_{4}\left(C_{\mathrm{s}}-\mathrm{L}_{1}\right)$ in total. Two $\mathrm{Br}_{2}$ molecules in $\mathrm{Br}_{4}\left(C_{\mathrm{s}}-\mathrm{L}_{1}\right)$ will supply a wider area for electrons without severe disadvantageous steric compression by the L-shaped structure in a plane. The structural feature of $\mathrm{Br}_{4}\left(C_{\mathrm{s}}-\mathrm{L}_{1}\right)$ may reduce (or may not severely increase) the electron-electron repulsive terms, $\Delta\left(\left(\Sigma_{i \neq j}^{n} J_{i j}-\Sigma_{i \neq j, \|}{ }^{n} K_{i j}\right) / 2\right)$, relative to the case of $2 \mathrm{Br}_{2}$, although $\Delta \Sigma_{i}{ }^{n} H_{c}(i)$ seems to destabilize it. The $\Delta \Sigma_{i}{ }^{n} H_{c}(i)$ $+\Delta\left(\Sigma_{i \neq j}^{n} J_{i j}-\Sigma_{i \neq j, \|}{ }^{n} K_{i j}\right) / 2$ value is equal to $-10.7 \mathrm{~kJ} \mathrm{~mol}^{-1}$, which corresponds to the stabilization energy of $\mathrm{Br}_{4}\left(C_{\mathrm{s}}-\mathrm{L}_{1}\right)$, relative to $2 \mathrm{Br}_{2}$. 


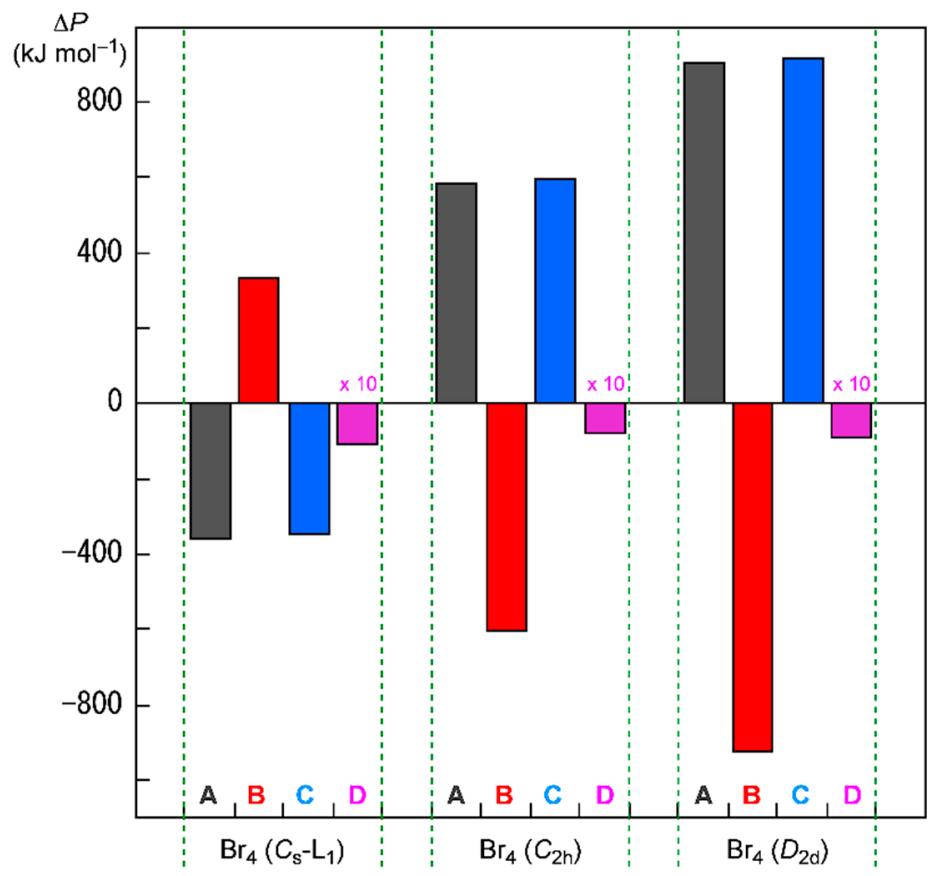

Figure 8. Contributions from $\Delta \Sigma_{i}{ }^{n} H_{c}(i)(=\Delta P=\mathbf{B})$ and $\Delta\left(\sum_{i \neq j}{ }^{n} J_{i j}-\Sigma_{i \neq j, \|^{n}} K_{i j}\right) / 2(=\Delta P=\mathbf{C})$ to $\Delta E_{\mathrm{ES}}$ $\left(=\Delta P=\mathbf{D}\right.$, magnified by 10 times in the plot) for $\mathrm{Br}_{4}\left(C_{\mathrm{s}}-\mathrm{L}_{1}\right), \mathrm{Br}_{4}\left(C_{2 \mathrm{~h}}\right)$, and $\mathrm{Br}_{4}\left(D_{2 \mathrm{~d}}\right)$, relative to $2 \mathrm{Br}_{2}$, together with $\Delta \Sigma_{i=1}^{n} \varepsilon_{i}(=\Delta P=\mathbf{A})$.

The energy profiles of $\mathrm{Br}_{4}\left(C_{2 \mathrm{~h}}\right)$ and $\mathrm{Br}_{4}\left(D_{2 \mathrm{~d}}\right)$ seem very different from that of $\mathrm{Br}_{4}$ $\left(C_{\mathrm{s}}-\mathrm{L}_{1}\right)$. The $\Delta \Sigma_{i=1}^{n} \varepsilon_{i}$ terms for $\mathrm{Br}_{4}\left(C_{2 \mathrm{~h}}\right)$ and $\mathrm{Br}_{4}\left(D_{2 \mathrm{~d}}\right)$ are evaluated to be 587.5 and 908.1 kJ mol ${ }^{-1}$, respectively. Namely, $\mathrm{Br}_{4}\left(C_{2 \mathrm{~h}}\right)$ and $\mathrm{Br}_{4}\left(D_{2 \mathrm{~d}}\right)$ would be less stable than $2 \mathrm{Br}_{2}$ if $\Delta \Sigma_{i=1}^{n} \varepsilon_{i}$ are compared. Consequently, it is difficult to explain the stability of $\mathrm{Br}_{4}\left(C_{2 h}\right)$ and $\mathrm{Br}_{4}\left(D_{2 \mathrm{~d}}\right)$, based on the MO energies. On the other hand, $\Delta \Sigma_{i}{ }^{n} H_{c}(i)$ of $\mathrm{Br}_{4}\left(C_{2 \mathrm{~h}}\right)$ and $\mathrm{Br}_{4}$ $\left(D_{2 \mathrm{~d}}\right)$ are evaluated to be -603.5 and $-926.3 \mathrm{~kJ} \mathrm{~mol}^{-1}$, respectively, whereas $\Delta\left(\Sigma_{i \neq j}{ }^{n} J_{i j}\right.$ $\left.-\Sigma_{i \neq j, \|^{n}} K_{i j}\right) / 2$ are 595.5 and $917.2 \mathrm{~kJ} \mathrm{~mol}^{-1}$, respectively. As a result, the $\left(\Delta \Sigma_{i}^{n} H_{c}(i)+\right.$ $\left.\Delta\left(\sum_{i \neq j}{ }^{n} J_{i j}-\Sigma_{i \neq j, \|}{ }^{n} K_{i j}\right) / 2\right)$ values are -8.0 and $-9.1 \mathrm{~kJ} \mathrm{~mol}^{-1}$ for $\mathrm{Br}_{4}\left(C_{2 \mathrm{~h}}\right)$ and $\mathrm{Br}_{4}\left(D_{2 \mathrm{~d}}\right)$, respectively, which correspond to their $\Delta E_{\mathrm{ES}}$ values (relative to $2 E\left(\mathrm{Br}_{2}\right)$ ). The results show that the stabilizing effect of $\Delta \Sigma_{i}^{n} H_{c}(i)$ overcomes the shorter electron-nuclear distances in the species on average. The shorter electron-electron distances must destabilize $\mathrm{Br}_{4}\left(C_{2 \mathrm{~h}}\right)$ and $\operatorname{Br}_{4}\left(D_{2 \mathrm{~d}}\right)$ through the factor of $\Delta\left(\Sigma_{i \neq j}^{n} J_{i j}-\Sigma_{i \neq j, \|}{ }^{n} K_{i j}\right) / 2$, which is the inverse effect from the electron-nuclear interaction on $\Delta \Sigma_{i}^{n} H_{c}(i)$. However, the effect of the shorter distances on $\Delta \Sigma_{i}^{n} H_{c}(i)$ seems to contribute more effectively than the case of $\Delta\left(\Sigma_{i \neq j}{ }^{n} J_{i j}-\right.$ $\Sigma_{i \neq j, \|} \|_{i j} K_{i j} / 2$ in $\mathrm{Br}_{4}\left(C_{2 \mathrm{~h}}\right)$ and $\mathrm{Br}_{4}\left(D_{2 \mathrm{~d}}\right)$, although they are not so large.

How can the BPs in $\mathrm{Br}_{4}\left(C_{2 \mathrm{~h}}\right)$ and $\mathrm{Br}_{4}\left(D_{2 \mathrm{~d}}\right)$ be rationalized through orbital interactions? The $\Delta \varepsilon_{i}$ values of $\mathrm{Br}_{4}\left(C_{2 h}\right)$ are positive for all occupied MOs, relative to the corresponding values of $2 \mathrm{Br}_{2}$, except for HOMO-3 $\left(-5.5 \mathrm{~kJ} \mathrm{~mol}^{-1}\right)$, HOMO-6 (-2.9 $\left.\mathrm{kJ} \mathrm{mol}^{-1}\right)$, HOMO-7 $\left(-35.8 \mathrm{~kJ} \mathrm{~mol}^{-1}\right)$, and HOMO-13 $\left(-1.1 \mathrm{~kJ} \mathrm{~mol}^{-1}\right)$. Figure 9 illustrates the interactions to produce HOMO, HOMO-3, HOMO-4, and HOMO-7. Indeed, HOMO-7 seems to contribute well to stabilizing $\mathrm{Br}_{4}\left(C_{2 \mathrm{~h}}\right)$, but HOMO-4 $\left(+40.8 \mathrm{~kJ} \mathrm{~mol}^{-1}\right)$ is also formed in the $\pi\left(\mathrm{Br}_{2}\right)-\pi\left(\mathrm{Br}_{2}\right)$ mode. Similarly, $\mathrm{HOMO}\left(+13.7 \mathrm{~kJ} \mathrm{~mol}^{-1}\right)$ is formed, together with HOMO-3 in the $\pi^{*}\left(\mathrm{Br}_{2}\right)+\pi^{*}\left(\mathrm{Br}_{2}\right)$ mode. Therefore, all MOs seem not to contribute to stabilizing $\mathrm{Br}_{4}\left(C_{2 \mathrm{~h}}\right)$ inherently. Nevertheless, HOMO, HOMO-4, and HOMO-7 seem to rationalize the appearance of $\mathrm{BPs}$ in $\mathrm{Br}_{4}\left(C_{2 \mathrm{~h}}\right)$, along the diagonal line and shorter sides of the parallelogram, although all electrons contribute to the appearance of BPs in molecules. 


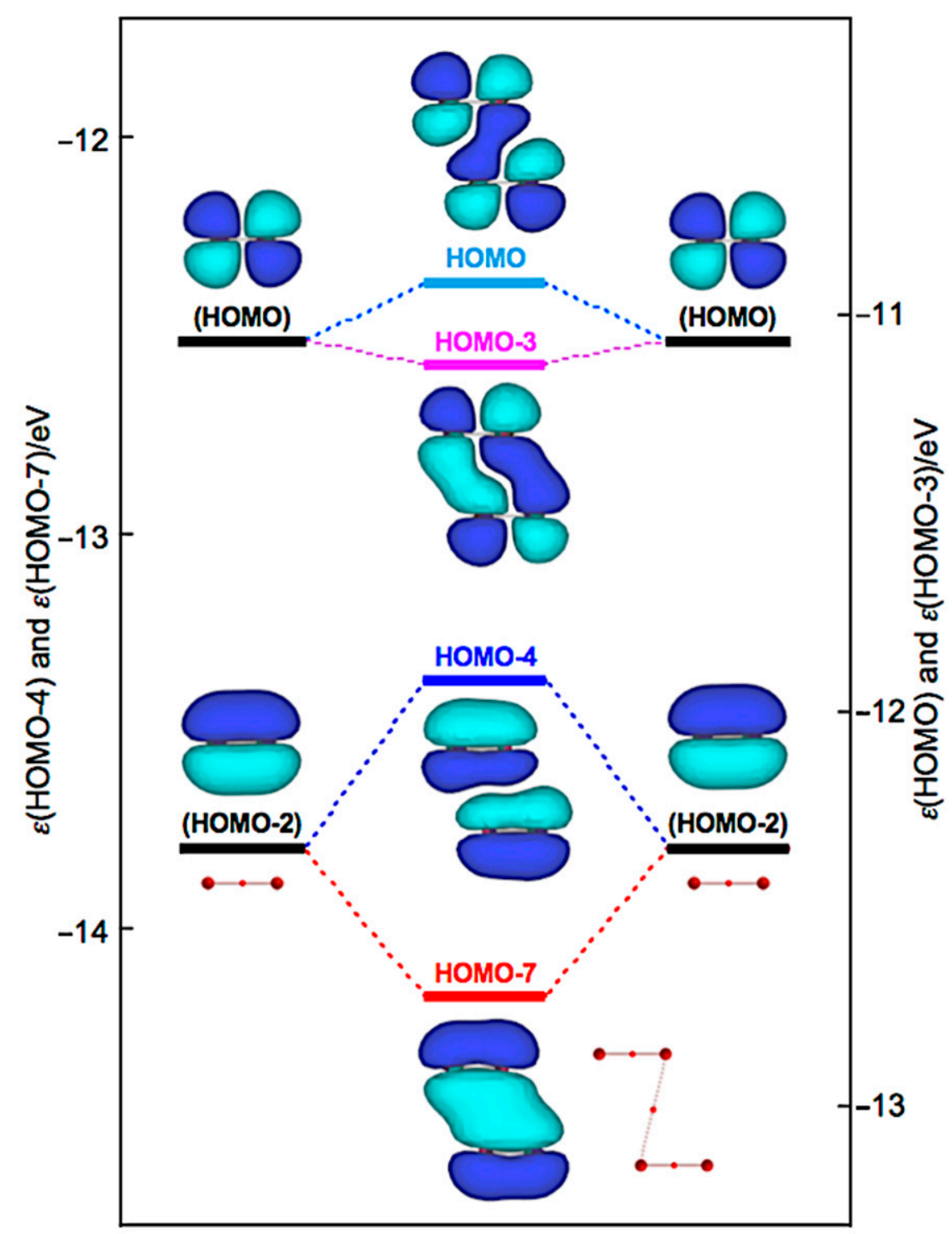

Figure 9. Energy profile for the formation of $\mathrm{Br}_{4}\left(C_{2 h}\right)$, exemplified by HOMO, HOMO-3, HOMO-4, and HOMO-7.

Similarly, $\Delta \varepsilon_{i}$ of $\mathrm{Br}_{4}\left(D_{2 \mathrm{~d}}\right)$ are positive for all occupied MOs, relative to the corresponding values of $2 \mathrm{Br}_{2}$, except for HOMO-3 (-1.9 $\left.\mathrm{kJ} \mathrm{mol}^{-1}\right), \mathrm{HOMO}-7\left(-39.2 \mathrm{~kJ} \mathrm{~mol}^{-1}\right)$, and HOMO-13 $\left(-0.5 \mathrm{~kJ} \mathrm{~mol}^{-1}\right)$. Figure 10 illustrates the interactions to produce $\mathrm{HOMO}$, HOMO-3, HOMO-4, and HOMO-7 in $\mathrm{Br}_{4}\left(D_{2 \mathrm{~d}}\right)$. HOMO-4 $\left(+50.2 \mathrm{~kJ} \mathrm{~mol}^{-1}\right)$ is formed through the $\pi\left(\mathrm{Br}_{2}\right)-\pi\left(\mathrm{Br}_{2}\right)$ mode in addition to HOMO-7. Similarly, HOMO $(+13.9 \mathrm{~kJ}$ mol $\left.{ }^{-1}\right)$ is formed, accompanied by HOMO-3, in the $\pi^{*}\left(\mathrm{Br}_{2}\right)+\pi^{*}\left(\mathrm{Br}_{2}\right)$ mode. Therefore, no MOs essentially stabilize $\mathrm{Br}_{4}\left(D_{2 \mathrm{~d}}\right)$. However, the appearance of BPs along the longer and shorter diagonal lines of the tetrahedron of $\mathrm{Br}_{4}\left(D_{2 \mathrm{~d}}\right)$ seem to be rationalized by HOMO-7, together with HOMO-3 and HOMO-4, modifying the BPs, although BPs will appear as the whole properties of molecules. 


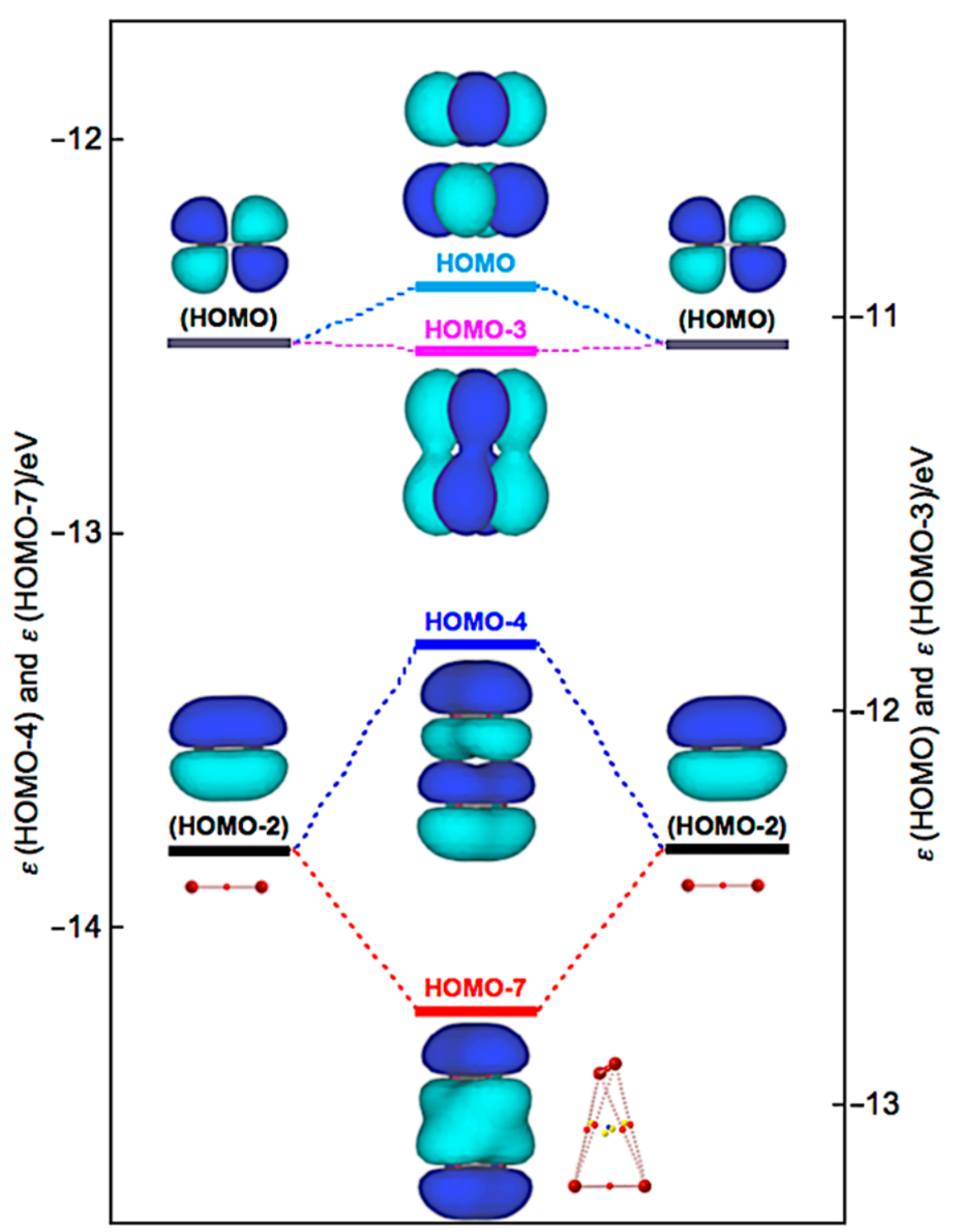

Figure 10. Energy profile for the formation of $\mathrm{Br}_{4}\left(D_{2 \mathrm{~d}}\right)$, exemplified by HOMO, HOMO-3, HOMO-4, and HOMO-7.

The nature of interactions in the charged clusters is also of interest. Such investigations are in progress.

\section{Conclusions}

The intrinsic dynamic and static nature of noncovalent $\mathrm{Br}-*-\mathrm{Br}$ interactions was elucidated for $\mathrm{Br}_{4}-\mathrm{Br}_{10}$ with MP2/6-311+G(3df). QTAIM-DFA was applied to the investigation. $H_{\mathrm{b}}\left(\boldsymbol{r}_{\mathrm{c}}\right)$ were plotted versus $H_{\mathrm{b}}\left(\boldsymbol{r}_{\mathrm{c}}\right)-V_{\mathrm{b}}\left(\boldsymbol{r}_{\mathrm{c}}\right) / 2$ for the interactions at BCPs of the fully optimized structures, together with those from the perturbed structures, generated with CIV. The nature of the covalent $\mathrm{Br}-*-\mathrm{Br}$ bonds in $\mathrm{Br}_{4}-\mathrm{Br}_{10}$ is predicted to have the SS/Cov-w nature if calculated with $\mathrm{MP} 2 / 6-311+\mathrm{G}(3 \mathrm{df})$. On the other hand, the nature of the noncovalent $\mathrm{Br}-*-\mathrm{Br}$ interactions in $\mathrm{Br}_{4}-\mathrm{Br}_{12}$ is classified by the pure CS interactions $\left(\theta \leq 76^{\circ}\right)$. The noncovalent $\mathrm{Br}-*-\mathrm{Br}$ interactions in the linear type clusters of $\mathrm{Br}_{4}\left(C_{\mathrm{s}}-\mathrm{L}_{1}\right)-\mathrm{Br}_{12}\left(C_{\mathrm{s}}-\mathrm{L}_{5}\right)$ are predicted to have the $p-\mathrm{CS} / t-\mathrm{HB}_{\mathrm{nc}}$ nature $\left(90.6^{\circ} \leq \theta_{\mathrm{p}}\right)$, except for $r_{2}$, outside the ones of the first end, which have the $p$-CS/vdW nature, although it is very close to the border area between the two $\left(\theta_{\mathrm{p}} \leq 89.4^{\circ}\right)$. In the case of the cyclic clusters, the noncovalent $\mathrm{Br}-*-\mathrm{Br}$ interactions will have the $p$-CS/vdW nature $\left(\theta_{\mathrm{p}} \leq 88.4^{\circ}\right)$, except for $r_{2}$ in $\operatorname{Br}_{8}\left(S_{4}\right)\left(\theta_{\mathrm{p}}=93.5^{\circ}\right)$ and $\mathrm{Br}_{8}\left(S_{4}-\mathrm{Wm}\right)\left(\theta_{\mathrm{p}}=95.3^{\circ}\right)$, which have the $p-\mathrm{CS} / t-\mathrm{HB}_{\mathrm{nc}}$ nature. 
The energies for $\mathrm{Br}_{3} \sigma(3 \mathrm{c}-4 \mathrm{e})$ of the $n_{\mathrm{p}}(\mathrm{Br}) \rightarrow \sigma^{*}(\mathrm{Br}-\mathrm{Br})$ type are well evaluated by not only $E(2)$ but also $C_{i i}{ }^{-1}$ for $\mathrm{Br}_{4}\left(C_{\mathrm{s}}-\mathrm{L}_{1}\right)-\mathrm{Br}_{12}\left(C_{\mathrm{s}}-\mathrm{L}_{5}\right)$. $E(2)$ correlates very well to $C_{i i}{ }^{-1}$. The CT interactions of the $n_{\mathrm{p}}(\mathrm{Br}) \rightarrow \sigma^{*}(\mathrm{Br}-\mathrm{Br})$ type must contribute to form $\mathrm{Br}_{4}\left(C_{\mathrm{s}}-\mathrm{L}_{1}\right)$, which can be explained based on the $\mathrm{MO}$ energies, $\varepsilon_{i}$. However, it seems difficult to explain the stability of $\mathrm{Br}_{4}\left(C_{2 \mathrm{~h}}\right)$ and $\mathrm{Br}_{4}\left(D_{2 \mathrm{~d}}\right)$ based on the energies. The $\mathrm{Br}_{2}$ molecules must be stacked more effectively in $\mathrm{Br}_{4}\left(C_{2 \mathrm{~h}}\right)$ and $\mathrm{Br}_{4}\left(D_{2 \mathrm{~d}}\right)$, resulting in shorter electronuclear distances on average. The energy lowering effect by $\Delta \Sigma_{i}{ }^{n} H_{\mathcal{C}}(i)$, due to the effective stacking of $2 \mathrm{Br}_{2}$ in $\mathrm{Br}_{4}\left(C_{2 \mathrm{~h}}\right)$ and $\mathrm{Br}_{4}\left(D_{2 \mathrm{~d}}\right)$, contributes to form the clusters, although the inverse contribution from $\Delta\left(\left(\Sigma_{i \neq j}^{n} J_{i j}-\Sigma_{i \neq j, \|^{n}} K_{i j}\right) / 2\right)$ must also be considered.

Supplementary Materials: The following are available online, Table S1: Structural parameters for $\mathrm{Br}_{2}-\mathrm{Br}_{6}$, Table S2: Structural parameters for $\mathrm{Br}_{8}-\mathrm{Br}_{12}$, Table S3: The bond path distances and the straight-line distances in the polybromide clusters, together with the differences between the two, Table S4: The $\rho_{\mathrm{b}}\left(\boldsymbol{r}_{\mathrm{c}}\right), H_{\mathrm{b}}\left(\boldsymbol{r}_{\mathrm{c}}\right)-V_{\mathrm{b}}\left(\boldsymbol{r}_{\mathrm{c}}\right) / 2\left(=\left(\hbar^{2} / 8 m\right) \nabla^{2} \rho_{\mathrm{b}}\left(\boldsymbol{r}_{\mathrm{c}}\right)\right)$, and $H_{\mathrm{b}}\left(\boldsymbol{r}_{\mathrm{c}}\right)$ values and QTAIM-DFA parameters for $\mathrm{Br}-*-\mathrm{Br}$ in polybromine clusters of $\mathrm{Br}_{2}-\mathrm{Br}_{12}$, Table S5: Contributions from the donoracceptor $(\mathrm{NBO}(i) \rightarrow \mathrm{NBO}(j))$ interactions of the $\mathrm{n}(\mathrm{Br}) \rightarrow \sigma^{*}(\mathrm{Br}-\mathrm{Br})$ type in the optimized structures of $\mathrm{Br}_{4}-\mathrm{Br}_{12}$, calculated using $\mathrm{NBO}$ analysis, Table S6: MO energies of $\mathrm{Br}_{4}\left(C_{2 h}\right)$, Table S7: MO energies of $\mathrm{Br}_{4}\left(D_{2 \mathrm{~d}}\right)$, Table S8: MO energies of $\mathrm{Br}_{2}\left(D_{\infty \mathrm{h}}\right)$, Table S9: MO energies of $\mathrm{Br}_{4}\left(C_{\mathrm{s}}-\mathrm{L}_{1}\right)$, Table S10: The $\Delta \varepsilon_{i}$ values for $\mathrm{Br}_{4}\left(C_{\mathrm{s}}-\mathrm{L}_{1}\right)$, relative to $2 \mathrm{Br}_{2}\left(D_{\infty \mathrm{h}}\right)$, Table S11: Energies for the $\mathrm{Br}_{4}$ clusters and $2 \mathrm{Br}_{2}$, together with the differences between the two, Figure S1: Plot of $\Delta E_{\mathrm{ZP}}$ versus $\Delta E_{\mathrm{ES}}$ for $\mathrm{Br}_{4}-\mathrm{Br}_{12}$, relative to those of $\mathrm{Br}_{2}$, respectively, Figure S2: Plots of $\Delta E_{\mathrm{ES}}$ for $\mathrm{Br}_{2}-\mathrm{Br}_{12}\left(C_{\mathrm{s}}-\mathrm{L}_{n}\right)$, Figure S3: Optimized structures for the cyclic bromine clusters of $\mathrm{Br}_{8}-\mathrm{Br}_{12}$, together with the linear type bromine cluster of $\mathrm{Br}_{10}$, Figure S4: Plot of $\theta$ and $\theta_{\mathrm{p}}$ versus $R$ for the noncovalent $\mathrm{Br}-*-\mathrm{Br}$ interactions at the BCPs in the fully optimized structures of $\mathrm{Br}_{4}-\mathrm{Br}_{12}$, Figure S5: Plot of $\theta_{\mathrm{p}}$ versus $\theta$ for the noncovalent $\mathrm{Br}-*-\mathrm{Br}$ interactions at the $\mathrm{BCPs}$ in the fully optimized structures of $\mathrm{Br}_{4}-\mathrm{Br}_{12}$, Figure $\mathrm{S6}$ : Plot of $E(2)$ versus $R$ for noncovalent $\mathrm{Br}-*-\mathrm{Br}$ interactions in $\mathrm{Br}_{4}\left(C_{\mathrm{s}}-\mathrm{L}_{1}\right)-\mathrm{Br}_{12}\left(C_{\mathrm{s}}-\mathrm{L}_{5}\right)$, Figure S7: Plot of $E(2)$ versus $\theta$ for noncovalent $\mathrm{Br}-*-\mathrm{Br}$ interactions in $\mathrm{Br}_{4}\left(C_{\mathrm{s}}-\mathrm{L}_{1}\right)-\mathrm{Br}_{12}\left(C_{\mathrm{s}}-\mathrm{L}_{5}\right)$, Figure S8: Plot of $E(2)$ versus $\theta_{\mathrm{p}}$ for noncovalent $\mathrm{Br}-*-\mathrm{Br}$ interactions in $\mathrm{Br}_{4}\left(C_{\mathrm{s}}-\mathrm{L}_{1}\right)-\mathrm{Br}_{12}\left(C_{\mathrm{s}}-\mathrm{L}_{5}\right)$, Figure S9: $\mathrm{MO}_{i}(i=70$, $67,64,35$, and 30 ) and the energies relative to those corresponding to $2 \mathrm{Br}_{2}$, and Cartesian coordinates and energies of all the species involved in the present work. Appendix: Survey of QTAIM, closely related to QTAIM dual-functional analysis; Criteria for classification of interactions: behavior of typical interactions elucidated by QTAIM-DFA; Characterization of interactions.

Author Contributions: S.H. and W.N. formulated the project. S.H., W.N., and T.N. optimized all compounds. T.N. and E.T. calculated the $\rho_{\mathrm{b}}\left(\boldsymbol{r}_{\mathrm{c}}\right), H_{\mathrm{b}}\left(\boldsymbol{r}_{\mathrm{c}}\right)-V_{\mathrm{b}}\left(\boldsymbol{r}_{\mathrm{c}}\right) / 2\left(=\left(\hbar^{2} / 8 m\right) \nabla^{2} \rho_{\mathrm{b}}\left(\boldsymbol{r}_{\mathrm{c}}\right)\right)$, and $H_{\mathrm{b}}\left(\boldsymbol{r}_{\mathrm{c}}\right)$ values and evaluated the QTAIM-DFA parameters and analyzed the data. S.H. and W.N. wrote the paper, while T.N. and E.T. organized the data to assist the writing. All authors have read and agreed to the published version of the manuscript.

Funding: Japan Society for the Promotion of Science, Grant Number 17K05785.

Data Availability Statement: Data are contained within the article or Supplementary Materials.

Acknowledgments: This work was partially supported by a Grant-in-Aid for Scientific Research (No. 26410050) from the Ministry of Education, Culture, Sports, Science, and Technology of Japan. Theoretical calculations were partially performed at the Research Centre for Computational Science, Okazaki, Japan.

Conflicts of Interest: The authors declare no conflict of interest.

\section{References and Notes}

1. Colin, J.J. Sur Quelques Combinaisons de l'Iode. Ann. Chim. 1814, 91, 252-272.

2. Cavallo, G.; Metrangolo, P.; Pilati, T.; Resnati, G.; Terraneo, G. Halogen Bond: A Long Overlooked Interaction. In Halogen Bonding I: Impact on Materials Chemistry and Life Sciences (Topics in Current Chemistry); Metrangolo, P., Resnati, G., Eds.; Springer: New York, NY, USA, 2015; Chapter 1; pp. 1-18.

3. Cavallo, G.; Metrangolo, P.; Milani, R.; Pilati, T.; Priimagi, A.; Resnati, G.; Terraneo, G. The Halogen Bond. Chem. Rev. 2016, 116, 2478-2601. [CrossRef]

4. Bent, H.A. Structural chemistry of donor-acceptor interactions. Chem. Rev. 1968, 68, 587-648. [CrossRef] 
5. Desiraju, G.R.; Parthasarathy, R. The nature of halogen halogen interactions: Are short halogen contacts due to specific attractive forces or due to close packing of nonspherical atoms? J. Am. Chem. Soc. 1989, 111, 8725-8726. [CrossRef]

6. Metrangolo, P.; Resnati, G. Halogen Bonding: A Paradigm in Supramolecular Chemistry. Chem. Eur. J. 2001, 7, 2511-2519. [CrossRef]

7. Erdélyi, M. Halogen bonding in solution. Chem. Soc. Rev. 2012, 41, 3547-3557. [CrossRef]

8. Beale, T.M.; Chudzinski, M.G.; Sarwar, M.G.; Taylor, M.S. Halogen bonding in solution: Thermodynamics and applications. Chem. Soc. Rev. 2013, 42, 1667-1680. [CrossRef] [PubMed]

9. Legon, A.C. Prereactive Complexes of Dihalogens XY with Lewis Bases B in the Gas Phase: A Systematic Case for the Halogen Analogue B $\cdots X Y$ of the Hydrogen Bond B HX. Angew. Chem. Int. Ed. 1999, 38, 2686-2714. [CrossRef]

10. Politzer, P.; Murray, J.S.; Clark, T. Halogen bonding and other $\sigma$-hole interactions: A perspective. Phys. Chem. Chem. Phys. 2013, 15, 11178-11189. [CrossRef]

11. Sugibayashi, Y.; Hayashi, S.; Nakanishi, W. Behavior of Halogen Bonds of the Y-X $\cdots$ Type $(\mathrm{X}, \mathrm{Y}=\mathrm{F}, \mathrm{Cl}, \mathrm{Br}, \mathrm{I})$ in the Benzene p System, Elucidated by Using a Quantum Theory of Atoms in Molecules Dual-Functional Analysis. Chem. Phys. Chem. 2016, 17, 2579-2589. [CrossRef] [PubMed]

12. Desiraju, G.R.; Ho, P.S.; Kloo, L.; Legon, A.C.; Marquardt, R.; Metrangolo, P.; Politzer, P.; Resnati, G.; Rissanen, K. Definition of the halogen bond (IUPAC Recommendations 2013). Pure Appl. Chem. 2013, 85, 1711-1713. [CrossRef]

13. Metrangolo, P.; Resnati, G. (Eds.) Halogen Bonding: Fundamentals and Applications; Series Structure and Bonding; Springer: New York, NY, USA, 2008.

14. Gierszal, K.P.; Davis, J.G.; Hands, M.D.; Wilcox, D.S.; Slipchenko, L.V.; Ben-Amotz, D. $\pi$-Hydrogen Bonding in Liquid Water. J. Phys. Chem. Lett. 2011, 2, 2930-2933. [CrossRef]

15. Categorizing Halogen Bonding and other Noncovalent Interactions Involving Halogen Atoms. a satellite event of the XXII Congress and General Assembly of the International Union of Crystallography, 2010; https:/ / doi.org/10.1515/ci.2010.32.2.20 (accessed on 1 May 2021).

16. Donohue, J.; Goodman, S.H. Interatomic distances in solid chlorine. Acta Cryst. 1965, 18, 568-569. [CrossRef]

17. Powell, B.M.; Heal, K.M.; Torrie, B.H. The temperature dependence of the crystal structures of the solid halogens, bromine and chlorine. Mol. Phys. 1984, 53, 929. [CrossRef]

18. Van Bolhuis, F.; Koster, P.B.; Migchelsen, T. Refinement of the crystal structure of iodine at 110 K. Acta Cryst. 1967, $23,90-91$. [CrossRef]

19. Schuster, P.; Mikosch, H.; Bauer, G. All electron density functional study of neutral and ionic polybromine clusters. J. Chem. Phys. 1998, 109, 1833-1844. [CrossRef]

20. Sung, D.; Park, N.; Park, W.; Hong, S. Formation of polybromine anions and concurrent heavy hole doping in carbon nanotubes. Appl. Phys. Lett. 2007, 90, 093502. [CrossRef]

21. Nakanishi, W.; Hayashi, S.; Narahara, K. Polar Coordinate Representation of $H_{\mathrm{b}}\left(r_{\mathrm{c}}\right)$ versus $\left(\hbar^{2} / 8 m\right) \nabla^{2} \rho_{\mathrm{b}}\left(r_{\mathrm{c}}\right)$ at BCP in AIM Analysis: Classification and Evaluation of Weak to Strong Interactions. J. Phys. Chem. A 2009, 113, 10050-10057. [CrossRef]

22. Nakanishi, W.; Hayashi, S. Atoms-in-Molecules Dual Functional Analysis of Weak to Strong Interactions. Curr. Org. Chem. 2010, 14, 181-197. [CrossRef]

23. Nakanishi, W.; Hayashi, S. Dynamic Behaviors of Interactions: Application of Normal Coordinates of Internal Vibrations to AIM Dual Functional Analysis. J. Phys. Chem. A 2010, 114, 7423-7430. [CrossRef]

24. Nakanishi, W.; Hayashi, S.; Matsuiwa, K.; Kitamoto, M. Applications of Normal Coordinates of Internal Vibrations to Generate Perturbed Structures: Dynamic Behavior of Weak to Strong Interactions Elucidated by Atoms-in-Molecules Dual Functional Analysis. Bull. Chem. Soc. Jpn. 2012, 85, 1293-1305. [CrossRef]

25. Nakanishi, W.; Hayashi, S. Role of $\mathrm{d} G / \mathrm{d} w$ and $\mathrm{d} V / \mathrm{d} w$ in AIM Analysis: An Approach to the Nature of Weak to Strong Interactions. J. Phys. Chem. A 2013, 117, 1795-1803. [CrossRef] [PubMed]

26. Bader, R.F.W. Atoms in Molecules. A Quantum Theory; Oxford University Press: Oxford, UK, 1990.

27. Matta, C.F.; Boyd, R.J. An Introduction to the Quantum Theory of Atoms in Molecules. In The Quantum Theory of Atoms in Molecules: From Solid State to DNA and Drug Design; WILEY-VCH: Weinheim, Germany, 2007.

28. Nakanishi, W.; Hayashi, S.; Nishide, T. Intrinsic dynamic and static nature of each HB in the multi-HBs between nucleobase pairs and its behavior, elucidated with QTAIM dual functional analysis and QC calculations. RSC Adv. 2020, 10, 24730-24742. [CrossRef]

29. See also Figure 5 for the definition of $(R, \theta)$ and $\left(\theta_{\mathrm{p}}, \kappa_{\mathrm{p}}\right)$, exemplified by the $r_{9}$ in $\mathrm{Br}_{10}\left(C_{\mathrm{s}}-L_{5}\right)$.

30. Nakanishi, W.; Hayashi, S. Perturbed structures generated using coordinates derived from compliance constants in internal vibrations for QTAIM dual functional analysis: Intrinsic dynamic nature of interactions. Int. J. Quantum Chem. 2018, 118, e25590-e25591. [CrossRef]

31. The basic concept for the compliance constants was introduced by Taylor and Pitzer, followed by Konkoli and Cremer.

32. Taylor, W.T.; Pitzer, K.S. Vibrational frequencies of semirigid molecules: A general method and values for ethylbenzene. J. Res. Natl. Bur. Stand. 1947, 38, 1-17. [CrossRef]

33. Konkoli, Z.; Cremer, D. A new way of analyzing vibrational spectra. I. Derivation of adiabatic internal modes. Int. J. Quantum Chem. 1998, 67, 1-9. [CrossRef] 
34. The $C_{\mathrm{ij}}$ are defined as the partial second derivatives of the potential energy due to an external force, as shown in Equations (R1), where $i$ and $j$ refer to internal coordinates, and the external force components acting on the system $f_{\mathrm{i}}$ and $f_{\mathrm{j}}$ correspond to $i$ and $j$, respectively.

35. $C_{\mathrm{ij}}=\partial^{2} E / \partial f_{\mathrm{i}} \partial f_{\mathrm{j}} \quad(\mathrm{R} 1)$.

36. The $C_{\mathrm{ij}}$ Values and the Coordinates Corresponding to $C_{\mathrm{ii}}$ Were Calculated by Using the Compliance 3.0.2 Program Released by Grunenberg, J. and Brandhorst, K. Available online: http:/ / www.oc.tu-bs.de/Grunenberg/compliance.html (accessed on 1 May 2021).

37. Brandhorst, K.; Grunenberg, J. Efficient computation of compliance matrices in redundant internal coordinates from Cartesian Hessians for nonstationary points. J. Chem. Phys. 2010, 132, 184101. [CrossRef]

38. Brandhorst, K.; Grunenberg, J. How strong is it? The interpretation of force and compliance constants as bond strength descriptors. Chem. Soc. Rev. 2008, 37, 1558-1567. [CrossRef] [PubMed]

39. Grunenberg, J. III-defined concepts in chemistry: Rigid force constants vs. compliance constants as bond strength descriptors for the triple bond in diboryne. Chem. Sci. 2015, 6, 4086-4088. [CrossRef] [PubMed]

40. Frisch, M.J.; Trucks, G.W.; Schlegel, H.B.; Scuseria, G.E.; Robb, M.A.; Cheeseman, J.R.; Scalmani, G.; Barone, V.; Mennucci, B.; Petersson, G.A.; et al. Gaussian 09 (Revision D.01), Gaussian, Inc.: Wallingford, CT, USA, 2009.

41. Binning, R.C.; Curtiss, L.A. Compact contracted basis sets for third-row atoms: Ga-Kr. J. Comput. Chem. 1990, 11, 1206-1216. [CrossRef]

42. Curtiss, L.A.; McGrath, M.P.; Blaudeau, J.-P.; Davis, N.E.; Binning, R.C., Jr.; Radom, L. Extension of Gaussian-2 theory to molecules containing third-row atoms Ga-Kr. J. Chem. Phys. 1995, 103, 6104-6113. [CrossRef]

43. McGrath, M.P.; Radom, L. Extension of Gaussian-1 (G1) theory to bromine-containing molecules. J. Chem. Phys. 1991, 94, 511-516. [CrossRef]

44. Clark, T.; Chandrasekhar, J.; Spitznagel, G.W.; Schleyer, P.v.R. Efficient diffuse function-augmented basis sets for anion calculations. III. The 3-21+G basis set for first-row elements, Li-F. J. Comput. Chem. 1983, 4, 294-301. [CrossRef]

45. Møller, C.; Plesset, M.S. Note on an Approximation Treatment for Many-Electron Systems. Phys. Rev. 1934, 46, 618-622. [CrossRef]

46. Gauss, J. Effects of electron correlation in the calculation of nuclear magnetic resonance chemical shifts. J. Chem. Phys. 1993, 99, 3629-3643. [CrossRef]

47. Gauss, J. Accurate Calculation of NMR Chemical Shifts. Ber. Bunsen-Ges. Phys. Chem. 1995, 99, 1001-1008. [CrossRef]

48. Biegler-König, F.; Schönbohm, J. The AIM2000 Program (Version 2.0). Available online: http:/ / www.aim2000.de (accessed on 1 May 2021).

49. Biegler-König, F. Calculation of atomic integration data. J. Comput. Chem. 2000, 21, 1040-1048. [CrossRef]

50. Keith, T.A. AIMAll (Version 17.11.14), TK Gristmill Software, Overland Park KS, USA. 2017. Available online: http://aim. tkgristmill.com (accessed on 1 May 2021).

51. See Figure 3 for $\mathrm{Br}_{4}-\mathrm{Br}_{12}$ of the L-shaped clusters in the $C_{\mathrm{s}}$ symmetry, $\mathrm{Br}_{4}\left(C_{\mathrm{s}}-\mathrm{L}_{1}\right)-\mathrm{Br}_{12}\left(C_{\mathrm{s}}-\mathrm{L}_{5}\right)$, and Figure 4 for $\mathrm{Br}_{6}-\mathrm{Br}_{12}$ of the cyclic bromine clusters.

52. See also Entry 1 in Table 3. http:/ / aim.tkgristmill.com/ (accessed on 1 May 2021).

53. The $\mathrm{Br}-\mathrm{Br}$ distance in $\mathrm{Br}_{2}$ was optimized to be $2.2806 \AA$ with $\mathrm{MP} 2 / 6-311+\mathrm{G}(3 \mathrm{df})$, which was very close to the observed distance in the gas phase $(2.287 \AA)$. However, the values are shorter than that determined by the X-ray crystallographic analysis $(2.491 \AA)$ by $0.210 \AA$. The non-covalent $\mathrm{Br}-\mathrm{Br}$ distance is $3.251 \AA$ in crystal, which is shorter than the sum of the van der Waals radii by $0.45 \AA$.

54. Bondi, A. van der Waals Volumes and Radii. J. Phys. Chem. 1964, 68, 441-451. [CrossRef]

55. The molecular graph for $\mathrm{Br}_{4}\left(C_{2 h}\right)$ was very complex and very different from that expected for it when calculated with MP2/6$311+\mathrm{G}(3 \mathrm{df}) / / \mathrm{MP} 2 / 6-311+\mathrm{G}(3 \mathrm{df})$. Some $(\omega, \sigma)=(3,-3)$ attractors appear in the molecular graph of $\mathrm{Br}_{4}\left(C_{2 \mathrm{~h}}\right)$, which do not correspond to bromine atoms. Therefore, the molecular graph for $\mathrm{Br}_{4}\left(C_{2 h}\right)$ were drawn with $\mathrm{MP} 2 / 6-311+\mathrm{G}(\mathrm{d}) / / \mathrm{MP} 2 / 6-$ $311+\mathrm{G}(3 \mathrm{df})$, which was shown in Figure 2. The $\rho_{\mathrm{b}}\left(\boldsymbol{r}_{\mathrm{c}}\right), H_{\mathrm{b}}\left(\boldsymbol{r}_{\mathrm{c}}\right)-V_{\mathrm{b}}\left(\boldsymbol{r}_{\mathrm{c}}\right) / 2\left(=\left(\hbar^{2} / 8 m\right) \nabla^{2} \rho_{\mathrm{b}}\left(r_{\mathrm{c}}\right)\right)$, and $H_{\mathrm{b}}\left(\boldsymbol{r}_{\mathrm{c}}\right)$ values were calculated with the same method.

56. Glendening, E.D.; Reed, A.E.; Carpenter, J.E.; Weinhold, F. NBO, Gaussian, Inc.: Pittsburgh, PA, USA, 2003 ; version 3.1. 